\title{
What we think we know about the aerodynamic performance of windows
}

\author{
Patrick Sharpe $^{\mathrm{a}}$, Benjamin Jones ${ }^{\mathrm{a}, *}$, Robin Wilson ${ }^{\mathrm{a}}$, Christopher Iddon ${ }^{\mathrm{b}}$ \\ ${ }^{a}$ Department of Architecture and Built Environment, University of Nottingham, \\ Nottingham, UK \\ ${ }^{b}$ Chartered Institution of Building Services Engineers Natural Ventilation Special Interest \\ Group, 222 Balham High Road, London, UK
}

\begin{abstract}
Natural ventilation is a low energy strategy used in many building types. Design approaches are mature but are dependent on variables with high uncertainty, such as the aerodynamic behaviour of purpose provided openings (PPOs), which need improved characterisation.

An analytical framework is used to define different types of flow through openings based on the balance of environmental forces that drive flow, and the different flow structures they create. This allows a comprehensive literature review to be made, where different studies and descriptive equations can be compared on a like-for-like basis, and from which clear gaps in knowledge, technical standards, and design data are identified. Phenomena whose understanding could be improved by analysis of existing data are identified and explored.
\end{abstract}

A Statistical Effective Area Model (SEAM) is developed from academic data to estimate the performance of butt hinged openings during the design

\footnotetext{
* Corresponding author

Email address: benjamin.jones@nottingham.ac.uk (Benjamin Jones)
} 
stage, that accounts for the impact of aspect ratio and opening angle. Its predictions are compared against available empirical data and are found to have a standard error of $1.2 \%$, which is substantially lower that the $15-25 \%$ prediction errors of free area models commonly used in practice.

An analytical model is made based on entrainment theory to explain the increase in flow rate that occurs through two aligned openings. This model defines characteristic design parameters and predicts a detrimental impact on the ventilation of the wider space.

Finally, an analytical model is created to explain the reduction in discharge coefficient that occurs when a large temperature difference exists across an opening. This model defines novel dimensionless parameters that characterise the flow, and predicts empirical data well, suggesting that is should be integrated into design equations.

Keywords: Purpose provided opening, ventilation, model, prediction, geometry, free area

\section{Highlights}

- Framework developed and used to determine aerodynamic performance

- Evaluation of existing literature

- Quantification of ambiguities implicit in existing modelling techniques

- Development of new analytical models 


\section{Introduction}

Natural ventilation is seen by many to be a crucial part of a low energy building strategy, but is sometimes perceived to be risky and unreliable.

To encourage the widespread use of natural ventilation, reliability issues need to be addressed. A major source of prediction error stems from a poor understanding of the aerodynamic performance of window openings (PPOs) and whole building systems $[1,2,3,4]$. This paper will show that techniques for modelling real openings are flawed, and create systematic errors in performance predictions that, when brought to light in the under-performance of the finished building [5], can damage the reputation of natural ventilation design. Improving these techniques will help design systems that are robust enough to perform under a wide range of environmental conditions, and help to restore confidence in the ability of natural ventilation to deliver efficient, functioning buildings.

Section 1 introduces the fundamental concepts behind envelope flow models and their approach to calculating air flow rates through openings. Section 2 develops a framework that systematically breaks down the assumptions made to simplify these calculations, and uses it to structure a comprehensive literature review into the behaviour of openings when these assumptions are violated. This review is used to identify key gaps in research, experimental data and technical standards. Some areas where understanding can be improved by analytical or statistical modelling are identified, and explored in Sections 3-5. Key conclusions from the work are summarised in Section 6. 


\subsection{Designing a ventilation strategy}

When designing a natural ventilation strategy for a building there are two key stages [6]. The first is to define the desired flow pattern of air within the building, which often varies seasonally to best satisfy occupant comfort. The second task is to design the envelope. This involves positioning and sizing openings so that the required airflow pattern and volume flow rates are achieved under the design conditions [7]. In practice, this is typically achieved using envelope flow models. The main attraction of these models is their simplicity: in many cases basic hand calculations suffice $[3,8,7]$.

\subsection{Principles of envelope flow models}

The fundamental concepts of envelope flow models are very simple, and can broadly be divided into two separable components $[3,8,7]$. The first is the calculation of the pressure differentials exerted on the building envelope that drive airflow through a building. These are caused by an interaction between the building geometry with wind and thermal buoyancy forces [9]. Empirical and experimental techniques for estimating these pressure distributions are given in $[3,8,10]$, with extensive data sets for generic building types given by [11]. The second component to predicting airflow through envelope flow models is the characterisation of the aerodynamic performance of openings in the building envelope that admit airflow. It is this second component that forms the basis of this paper.

Openings in a building envelope can be divided into two types: adventitious openings and purpose provided openings (PPOs) [2]. Adventitious openings are unintentional, and comprise cracks and gaps in the building envelope. PPOs are created intentionally as part of the ventilation scheme, and 
often take the form of operable windows or vents. All the theory described henceforth concerns PPOs, and assumes that adventitious openings account for a negligible fraction of overall ventilation rates.

\subsubsection{Key assumptions of the treatment of PPOs in envelope flow models}

In a conventional envelope flow model, several assumptions are made about the aerodynamic performance of PPOs to ensure their independence of calculations of driving pressure, and to simplify modelling of their resistance to airflow $[7,12,13,3,14]$. Some typical assumptions are:

- Openings in the envelope are small, so that they do not significantly alter the pressure distributions on the façade.

- PPOs can be treated as an equivalent sharp-edged orifice

- Internal and external density profiles are uniform across the height of the opening, and do not vary with flow rate

- Internal air motion is negligible

- Flow characteristics of openings in wind can be given by their still-air characteristics

- The pressure field across the opening is approximately uniform and equivalent to the pressure measured at its centre

- Ventilation is pseudo-steady - the time averaged flow characteristic is unaffected by turbulence 
To some extent these issues can be resolved by combining conventional envelope flow models with zonal models, dynamic thermal models, or computational fluid dynamics (CFD), but this comes at the cost of increased computational complexity and time [15].

\subsection{Theory of flow through openings}

In a conventional envelope flow model, airflow through PPOs is described by the orifice flow equation $[3,8,7]$. The names and definitions of the terms used in this equation vary between sources, particularly those describing measurements of area. Therefore, this paper follows the convention of Jones et al. [2] to avoid ambiguity.

The orifice flow equation can be derived trivially by application of the Bernoulli equation to a streamline passing through a constriction for the case where the ambient air is quiescent on either side of the opening $[7,10,3]$; see Figure 1. This relates the volume flow rate to the pressure drop in the constriction, and the minimum area through which the fluid passes.

$$
Q=A_{\min } \sqrt{\frac{2\left(P_{1}-P_{2}\right)}{\rho}}
$$

Here, $Q$ is the volume flow rate, $A_{\min }$ is the minimum area through which the fluid passes, and $P_{1}$ and $P_{2}$ are the static pressures on the streamline upstream of the constriction and at the point of maximum constriction respectively.

It is common in envelope flow models to treat PPOs as sharp-edged orifices $[7,4]$. When fluid flows through a sharp-edged opening, flow separation occurs at the edges. This results in a characteristic flow pattern where the 
fluid passes though a contracted area smaller than the opening, known as the vena contracta $[4,16]$; see Figure 1 . This represents the minimum area specified in Equation 1. The ratio of the area of the vena contracta, $A_{\min }$, to that of the opening, $A_{f}$, is the contraction coefficient $C_{c}$ [4]. The term $A_{f}$ is a geometric parameter associated with the opening known as the free area, and is commonly defined as the minimum unobstructed area perpendicular to the flow, although this varies between sources $[2,17,18]$. The flow separation caused by the sharp edges means that the value of the contraction coefficient does not vary significantly with Reynolds number [7]. An additional factor, $C_{f}$, is included to account for frictional resistance [4]. The product of these is termed the discharge coefficient, $C_{d}$, and results in the equation

$$
Q=C_{d} A_{f} \sqrt{\frac{2\left(P_{E}-P_{I}\right)}{\rho}}
$$

The discharge coefficient of a two dimensional slit can be derived theoretically, and evaluates to approximately 0.611 [19]. This is very close to experimentally derived values for a sharp edged circular orifice, which typically lie between 0.6 and $0.65[3,10]$. While the discharge coefficient would be expected to be different for different opening geometries, a discharge coefficient of circa 0.61 [8] or 0.65 [10] is commonly used to model any arbitrary PPO. Although the measurement of free area is trivial for a circular hole, it becomes much more complex and ambiguous for real PPO geometries; see Section 2.1.1. The product of the discharge coefficient and the free area is known as the effective area, $A_{\text {eff }}$, which represents the aerodynamic properties of the opening in still air. Equation 2 can then be rearranged to find the effective area of openings required to provide a given flow rate under the 

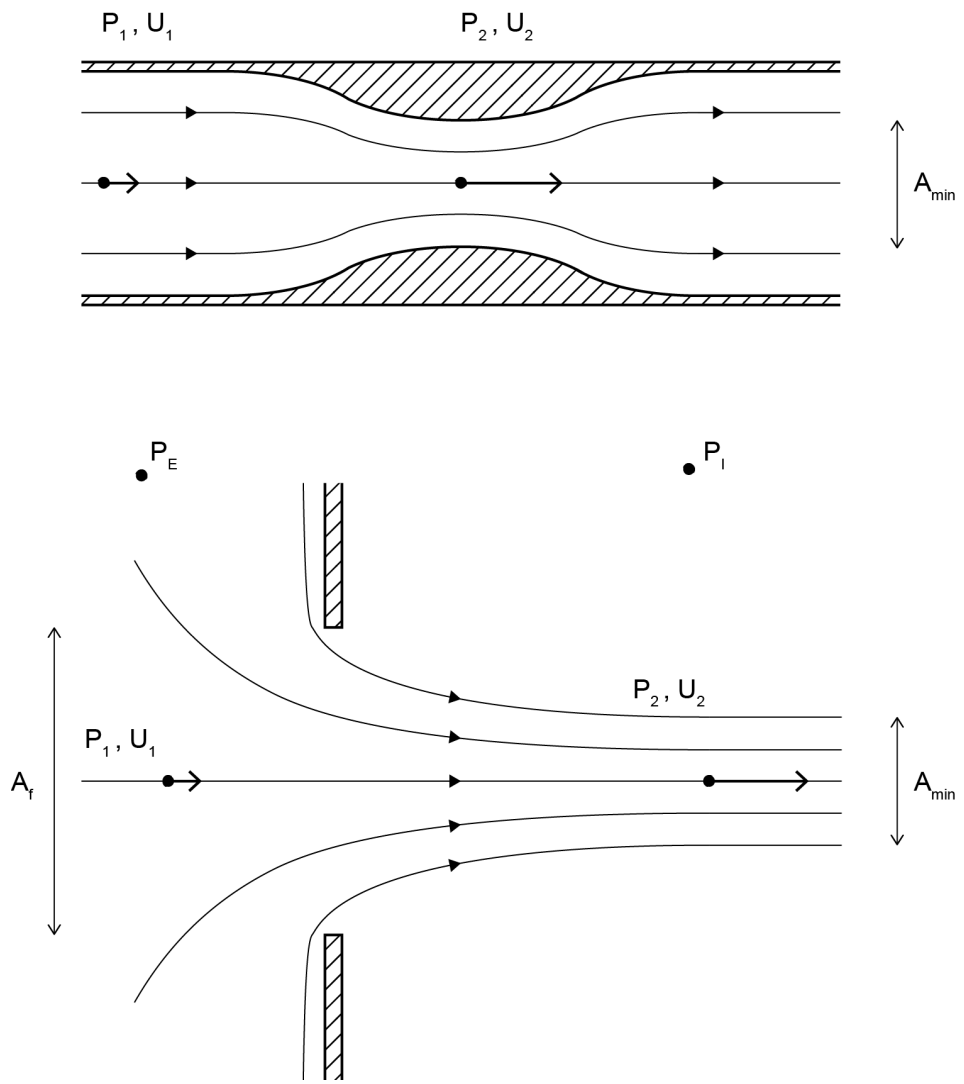

Figure 1: Comparison between the model of flow through a constriction (top), and its application to flow through a sharp-edged opening between an external (E) and internal

(I) space (bottom). 
design pressure difference. In off-design cases, the effective area can be used to evaluate airflow rates through the building under the influence of a range of weather conditions.

The fundamental theory is well understood, but when it is applied to real buildings many of the key assumptions of the orifice flow and envelope flow models are either violated (for example the still air assumption in wind driven flows) or only partially fulfilled (for example the still air assumption under light wind conditions) [4]. Consequently, when openings are installed in real buildings their aerodynamic performance often differs from that observed under laboratory conditions [6] or predicted by simple envelope flow models [12]. A good deal of research has been undertaken, both analytically and experimentally, to ascertain the causes of these deviations in aerodynamic performance, so that they can be adequately accounted for in the design process.

\section{Analytical framework for studying airflow through purpose pro- vided openings}

One advantage of creating a structured framework for analysing flow through openings, is that it enables the literature to be analysed systematically, gaps in the research to be identified, and the degree to which sources provide useful predictive tools to be assessed.

To make the analysis independent of building configuration, airflow through the openings is considered in isolation based on the environmental conditions at their internal and external surfaces. Here, the problem of estimating

flow through window openings is broken down into assumptions affecting the 
mechanisms that drive flow through them, and organised into a decision tree; see Figure 2. The performance of an opening can then be characterised using basic assumptions about the driving forces, and the impacts when each of these assumptions is invalid can be systematically investigated.

For convenience, the framework is broken down into three sections, which are shown in Figure 2. The upper section is the system definition, which outlines some of the key assumptions of the model geometry, the properties of the working fluid, and the flow structures present in the ambient environment. Below the system definition the tree is split into two sections: one where the external air is still, and the other where the external air is in motion. These allow the impact of the two mechanisms that drive flow - wind and buoyancy - to be evaluated both in isolation and in concert.

Sections 2.1-2.3 systematically describe the framework, and uses it to structure a review of the literature. Section 2.4 summarises the extent of knowledge identified using the framework, and identifies key gaps in the research.

\subsection{The system definition}

Figure 3 shows the system definition, which details some fundamental assumptions about the properties of the window and its environment that are required before simplified modelling methods can be applied. These assumptions are applicable to both still and moving air. The first two assumptions describe simplifications of model geometry; the third describes assumptions about fluid properties; and the final two assumptions describe the flow structures on the inside and outside of the opening. Resolving the final assumption divides the structure into two branches, describing conditions where the 


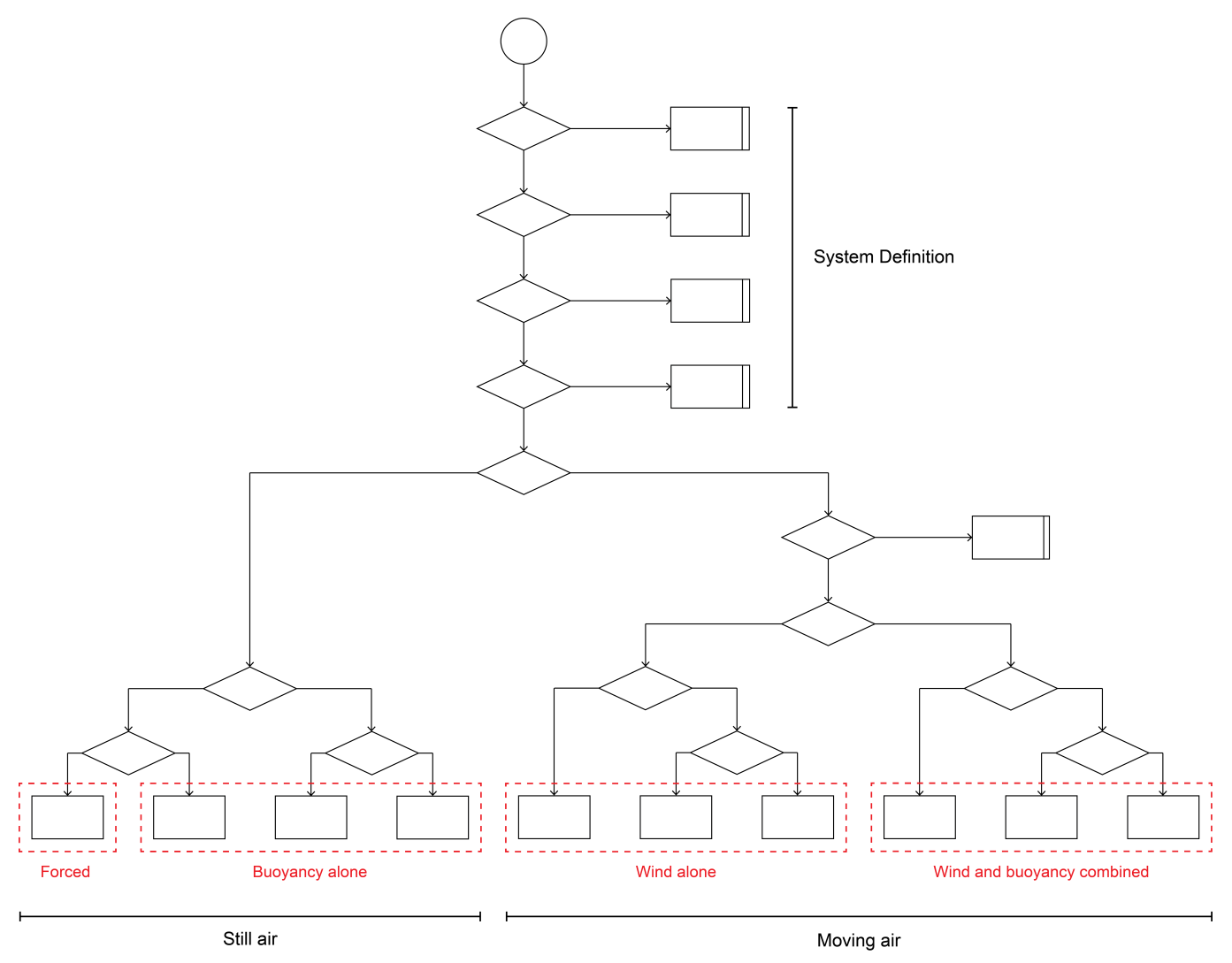

Figure 2: Overview diagram of analytical framework separating flow scenarios by driving mechanism and modelling assumptions. Branches of this framework are shown in detail in Figures 3, 7, and 8 
external air is still and in motion, respectively.

\subsubsection{Two-dimensional opening assumption}

One of the most common simplifications of model geometry assumes that any PPO can be modelled as a two-dimensional opening; see Section 1.3. Much of the literature uses the two-dimensional opening assumption explicitly, both in simplified physical models [20, 21, 22, 23] and CFD analysis [24, 25, 26, 27]. Many other sources study flow behaviour using threedimensional window geometries [28, 29, 30], but assume that they can be represented as two-dimensional openings using unvalidated area conversions. This makes it especially difficult to compare results between sources.

While the two-dimensional opening condition is well approximated for openings where all components share a common plane with the structural opening (such as sliding windows; see Figure 4), it cannot be said to be valid for opening geometries that contain elements that project from the plane of the structural opening. The projecting elements associated with three dimensional openings can act to restrict flow, alter the shape and direction of the streamlines passing through them, and change the way openings interact with external flow. A few studies directly examine the impact of complex opening geometry for cross ventilation [31, 32, 33], single sided ventilation $[34,35]$, and for specialised airflow units [36, 37], but this approach is not widespread.

When estimating airflow through an opening, it is necessary to characterise its resistance to airflow. For design purposes, the most important determinant of resistance is the effective area of the opening [3, 2]. While it is conventionally assumed that the flow capacity of an opening is depen- 


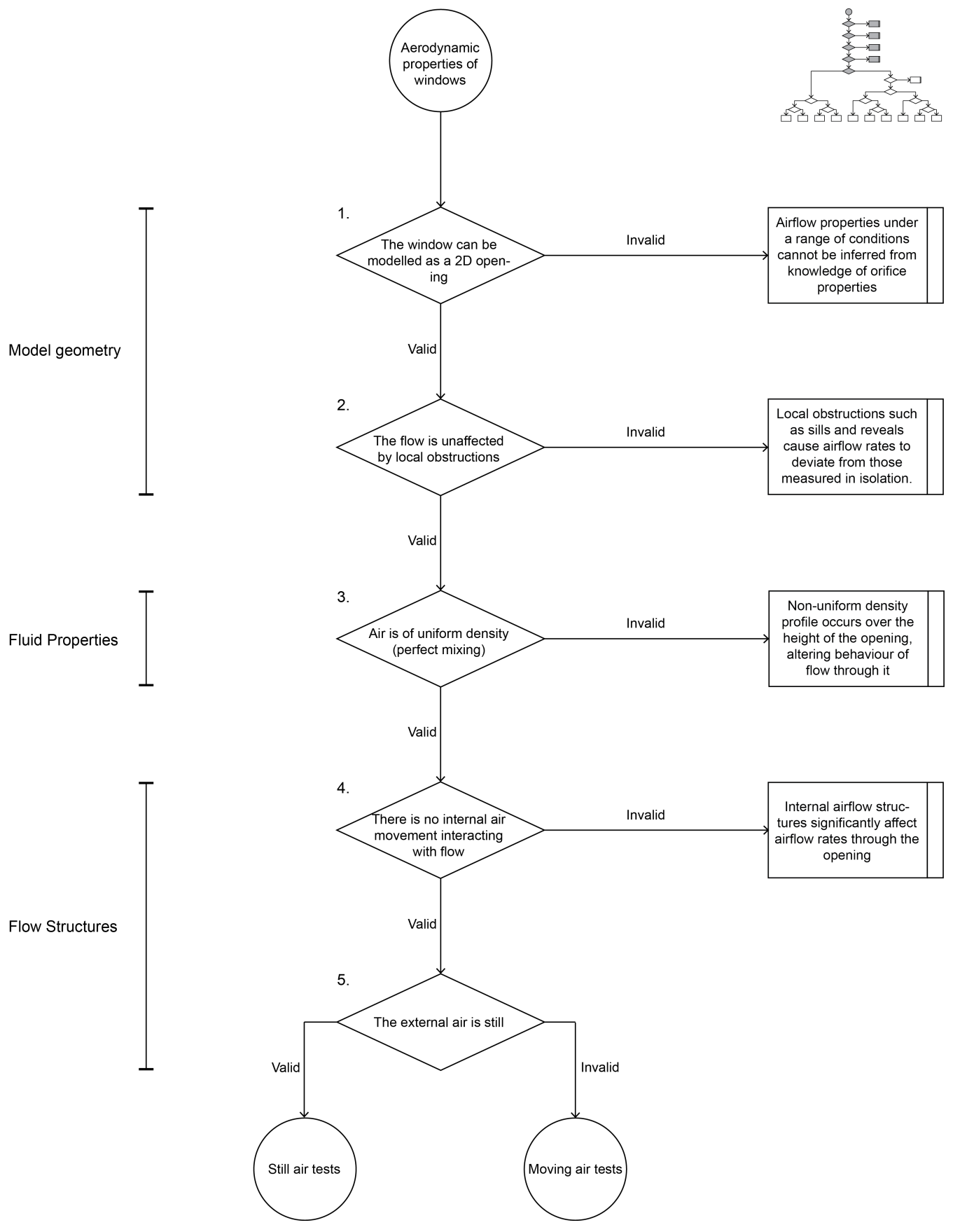

Figure 3: The system definition for the assumption tree detailing key assumptions about the nature of a ventilation opening and its environment. 

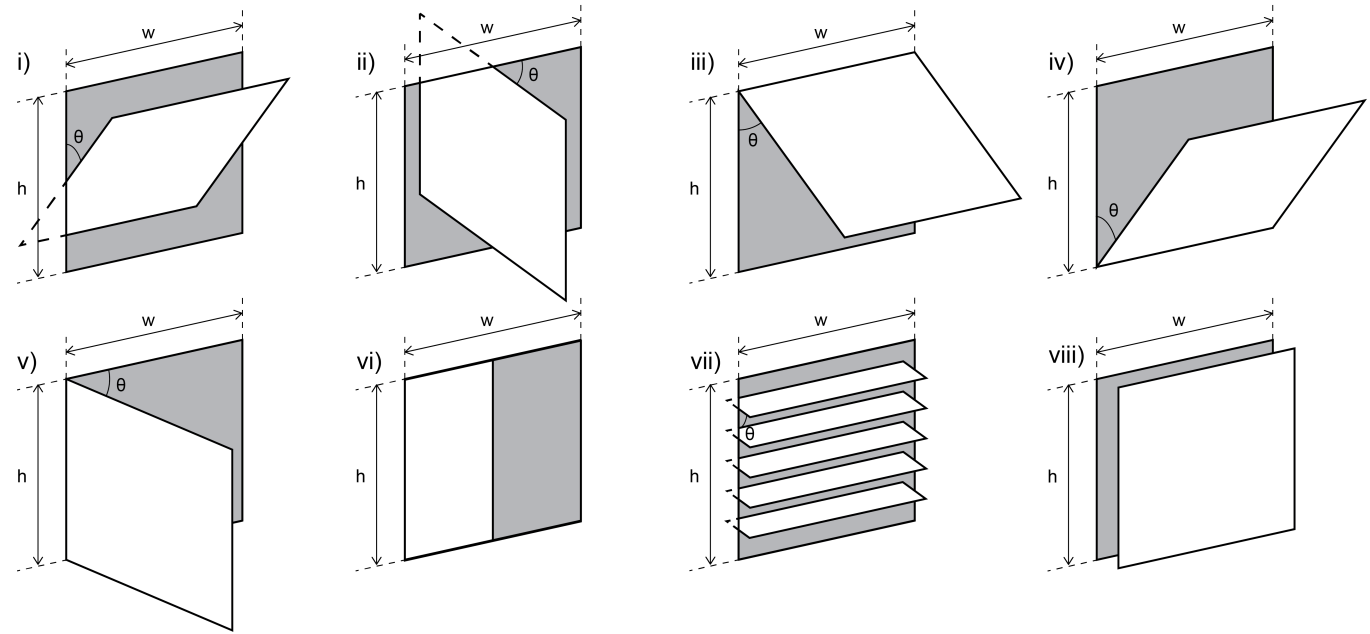

Figure 4: Common types of operable window: (i) horizontal pivot; (ii) vertical pivot; (iii) top hung; (iv) bottom hung; (v) side hung; (vi) sliding; (vii) louvre; (viii) parallel plate [39]

dant only on the total area [38], knowledge of the resistance distribution, and hence the area distribution, is required when the pressure across the opening is non-uniform. This effect is particularly important when the opening is very large compared to other openings in the ventilation system, or when all the openings are in similar locations in the pressure field.

2.1.1.1. Operable windows. One of the most common types of PPOs are operable windows. This paper follows the conventions given in CIBSE Guide B2 [39] for the naming of common window geometries shown in Figure 4. For the purposes of evaluating effective area, opening types (i-ii), and types (iii-v), can be considered identical, and are subsequently referred to as pivot and hinged openings, respectively.

In practice, it is common to calculate the effective area of an opening by assuming a constant discharge coefficient, and evaluating the free area based 
on inspection of the window geometry, given by

$$
A_{e f f}=C d A_{f}(\theta, h, w)
$$

where $\theta$ is the opening angle, $h$ is the height of the opening, $w$ is the width of the opening, and $A_{f} \leq h w$. Estimating the free area of a window is often assumed to be a trivial problem. Consequently, there has not been a systematic study of how this is done, or of the impacts of any errors associated with its estimation on predictions of window performance. However, it is clear from the literature that the definition of free area is ambiguous [2], and that different practitioners approach it in different ways. Figure 5 illustrates a range of approaches to calculating the free area of hinged openings, all of which are based on the sum of different measured areas. Little theoretical justification is given for each area model, and comparison with empirical data is very rare. This ambiguity is a major source of error both in practice and in academia [2].

Jong and Bot [31, 32] produce empirical data based on still-air pressurisation tests for simple hinged openings, which they use to fit coefficients to analytical free area model 'f' shown in Figure 5. This model however is unnecessarily complicated by a number of analytical factors that could be readily combined, and predicts effective areas that tend to infinity as the height to width ratio becomes large.

An alternative approach is to define a fixed, easily measurable area for an opening and to derive its discharge coefficient experimentally as a function of opening angle. This defines the effective area and the discharge coefficient as 


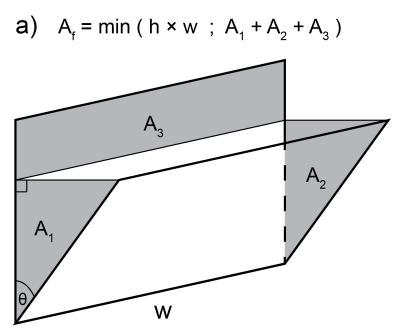

b) $A_{f}=\min \left(h \times w ; A_{1}+A_{2}+A_{3}\right)$
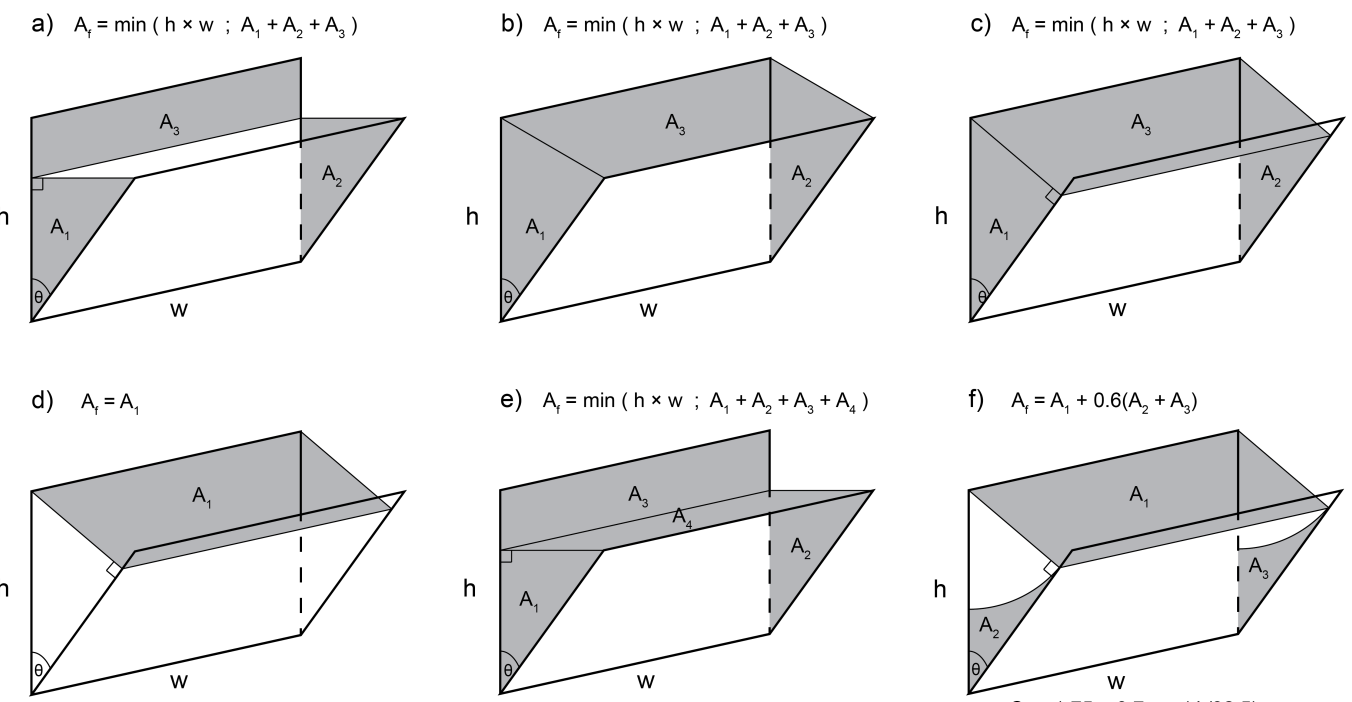

e) $A_{f}=\min \left(h \times w ; A_{1}+A_{2}+A_{3}+A_{4}\right)$

f) $A_{f}=A_{1}+0.6\left(A_{2}+A_{3}\right)$

$\mathrm{h}$
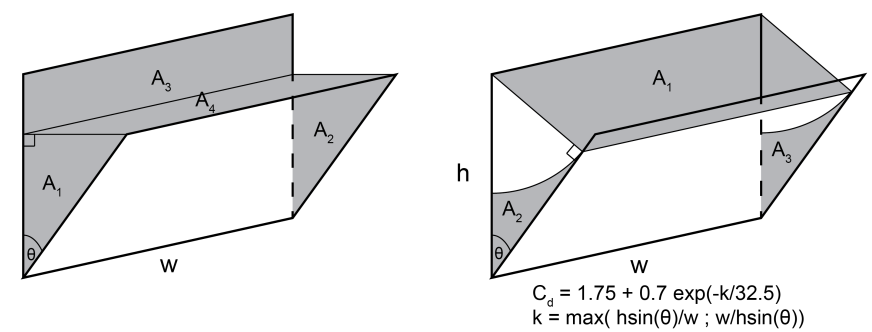

Figure 5: A range of different methods of modelling free area [28, 30, 34, 40, 31, 32, 18]. Model $f$ is semi-empirical, and includes a co-efficient allowing for reduced efficiency of the side areas that is adjusted to fit experimental data.

$$
\begin{aligned}
A_{e f f} & =C d(\theta, \sigma) h w \\
C d(\theta, \sigma) & =\frac{Q}{h w} \sqrt{\frac{\rho}{2 \Delta P}}
\end{aligned}
$$

where $\sigma$ is the aspect ratio, $h: w$. Figure 6 describes how the characteristic dimensions of a nominal window opening - its height, width, area, opening angle, and thickness - can be measured. Note that these definitions are applicable to all opening types given in Figure 4, as well as to windows that use sliding hinges where the pivot point moves in the vertical plane as $\theta$ varies.

The UK design guidance for the ventilation of school buildings, Building 

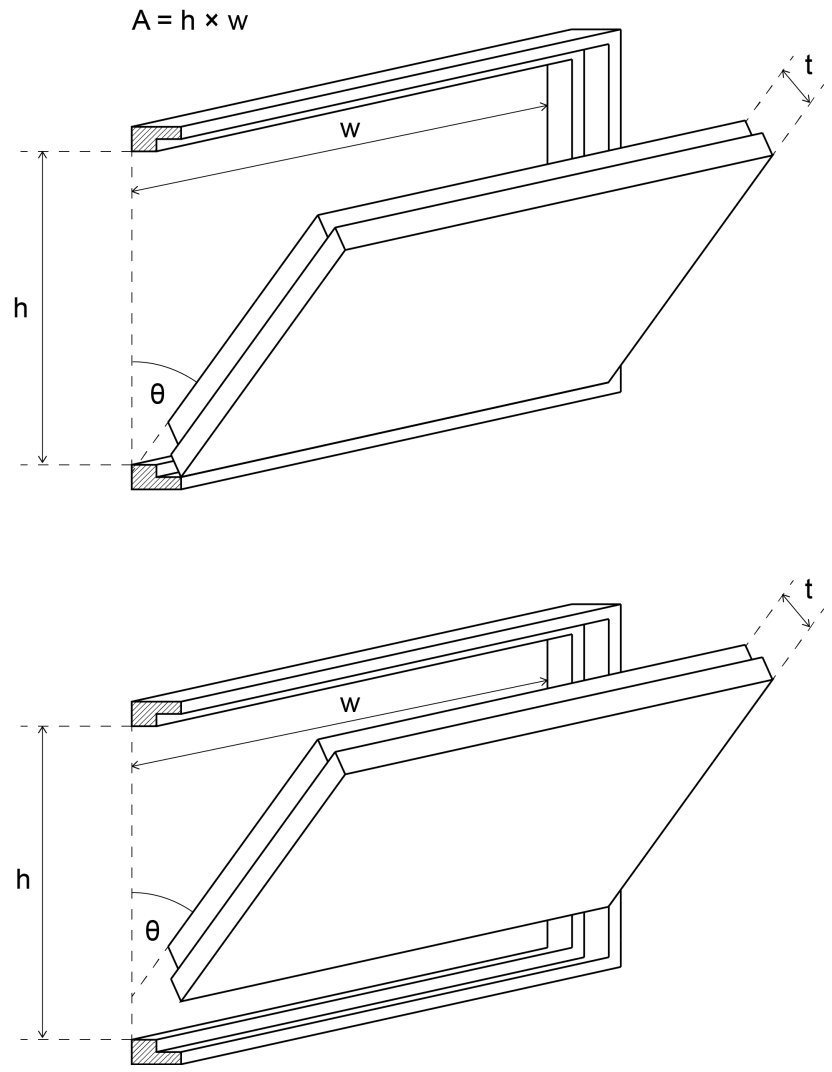

Figure 6: Simplified measurement method to define the dimensions and discharge coefficient of an opening, where $A$ is the free area of the opening, $h$ is the internal height of the fixed frame, $w$ is the internal width of the fixed frame, $t$ is the thickness of the opening sash, and $\theta$ is the angle between the planes of the fixed frame and opening sash

known as the opening angle. A summary of its application to different opening geometries is given in Figure 4. 
Bulletin 101 [41] (BB101), presents a simple statistical model of the variation in discharge coefficient with opening angle based on this approach, fitted to proprietary data ${ }^{1}$. A new statistical model that uses academic data [31, 32, $33]$ is developed in Section 3 for use in design, and benchmarked against existing models in Section 3.1.

\subsubsection{Chimneys, ducted outlets and wind catchers. A range of ventilation} technologies use long ducts to transport air around a building, either to access deeper spaces or provide access to favourable pressure conditions $[23,7]$. These opening types typically cannot be modelled as a sharp-edged orifice; their discharge coefficient needs to be given as a function of Reynolds number [7]. The use of Reynolds-dependent discharge coefficients allows these types of opening to be integrated into conventional envelope flow models.

In addition to their effect on discharge coefficient, these technologies affect the driving forces available for natural ventilation. Chimneys increase the stack height available for buoyancy ventilation $[7,8,3]$; solar chimneys increase the air temperature within the stack, raising buoyancy pressure; and wind catchers, chimney tops and roof cowls alter the wind pressure coefficients at the inlet/outlet to enhance flow $[15,42,3,7]$. While in many cases these pressures can be evaluated independently of flow rates through the ducts $[36,7,23]$, this is not universally true. As a result, purely empirical models are sometimes used to quantify the airflow performance of these components under a range of conditions [43].

\footnotetext{
${ }^{1}$ All versions available from DOI: $10.13140 /$ RG.2.2.10748.08323
} 
2.1.1.3. Mesh screens. To improve security and reduce the risk of ingress of bugs and animals, mesh screens are often installed in openings. Flow through these screens has been the subject of considerable study, and a summary of experimental data and modelling methods is given by Bailey et al. [44]. The discharge coefficient of screens are highly dependent on Reynolds's number $[7,44]$, and this relationship can be expressed as a function of the porosity of the screen and the thickness of the wires [44]. Alternatively, flow rates can be characterised by a power law [45] or quadratic relationship [7] instead of the conventional orifice flow equation.

\subsubsection{Unobstructed flow assumption}

To allow the properties of an opening to be determined separately from the room in which it is installed, it is often assumed that airflow rates are unaffected by local obstructions, such as sills and reveals. However, sills and reveals can restrict the area available for air to pass through, as well as affect how the window geometry interacts with external airflow.

In academia and in practice it is common for these local obstructions to be accounted for as a reduction in free area $[38,18]$. While the technique makes analytical sense, it is subject to the same ambiguities and errors associated with the geometric models discussed in Section 2.1.1.

The analytical technique developed by Hall [46] to improve the prediction of single sided ventilation rates was found to reduce errors in predicted performance at very small opening angles. However, the technique requires empirical data to calibrate it and no justification is given for extrapolating the results to higher opening angles or to cross ventilation configurations. In the absence of experimental data, the resultant errors cannot be quantified. 
In addition to the physical obstructions that occur due the installation position of a PPO within a building's fabric, it is possible that external obstacles - such as trees or louvres - or internal obstacles - such as people, blinds, furniture, and partitions - could interact with the structure of airflow through the openings. To the best of our knowledge there is no existing research that quantifies the effect of these obstacles on the performance of any PPO.

Mesh screens are typically installed within other opening types, and so have the potential to interact aerodynamically. Bailey et al. suggest calculating the combined resistance to airflow caused by a mesh screen set within a window frame by summing the resistance factors $\left(F=1 / C_{d}^{2}\right)$ determined for the two components in isolation, but provide no experimental data to support this. A similar approach might be applied to account for other internal obstacles. Tabulated design equations for the integration of mesh screens with louvres are given by Holzer and Psomas [42]. It is not clear how these screens would interact with other opening geometries.

\subsubsection{Uniform density assumption}

A common simplification of envelope flow models arises from the assumption that the air is of uniform density and perfectly mixed. This assumption is known to be invalid in most cases because hot air rises from heat sources, and stratifies near the ceiling $[22,47]$. This may have a significant impact on the pressures exerted across a window opening, resulting in substantial errors in the prediction of airflow rates. In this case, the bulk of the error is in the magnitude of the driving pressures and not the aerodynamic properties of the opening itself. Flow through the opening only behaves differently if the 
density profile is non-uniform across its height. A method of modelling a non-uniform density profile for a room is given in CIBSE AM10 [3], but this is unsubstantiated. Linden [47] develops a model based on plume physics describing thermal stratification, but this cannot account for the interaction between the range of heat sources and mixing mechanisms likely to be present in real buildings. Given that there is no effective method of predicting the density profile in a room [7], all analysis hereon assumes the density of the air is uniform across the height of the opening.

\subsubsection{Internal air movement assumption}

Envelope flow models commonly assume that the internal air is static; see Section 1.2.1. This assumption not only implies that the resistance to airflow caused by the internal space can be neglected, but that patterns of internal air movement cannot interfere with the dynamics of flow through the PPOs. In reality, internal air movement can come from a number of sources. Thermal plumes rising from occupants and machinery, gusting from mixing fans and turbulence from movements within the space can all play a role. These factors are complex to predict, and even when they are known it would be hard to design an experimental procedure to account for the range of possibilities. In CFD simulations, Shetabivash [25] identifies that the velocity profile of an opening is insignificantly altered by its location, despite the substantial variation in the internal flow pattern. This suggests that a study of internal air movement is unimportant for predicting bulk airflow, although it may be important in assessing local pollutant transport or thermal comfort. In contrast, Hall finds that the presence of an internal heater located below a bottom hung, inward opening window can reduce 
buoyancy driven single sided ventilation rates by up to $20 \%$ [46]. This is likely to be due to the fresh air supply entraining into the rising plume, which leaves the space without properly mixing with the room air. Given that it is common to locate emitters beneath windows to prevent cold downdraughts, further research into this phenomena is warranted.

Internal air motion has a greater impact on bulk flow rates when the inlet and outlet are in close proximity. Heiselberg and Sandberg [4] and Seifert et al. [48] identify the formation of a stream tube between the inlet and the outlet, where a flow connection causes kinetic energy to be conserved. Consequently, the conventional orifice flow equation tends to underestimate volume flow rates through the openings. This implies that ventilation systems over-perform the predictions of the orifice flow model [7] when openings are closely aligned. However, airflow within a stream tube may bypass the occupied portion of a room and be could be less effective at removing contaminants from there [10]. The shape of the streamlines approaching the opening would also be altered, which could alter the resistance to airflow provided by the opening. An analytical approach to modelling flow under these conditions is developed in Section 4. This is used to create predictive models for both bulk flow rates and pollutant removal rates and identify characteristic parameters.

\subsection{Performance in still air}

Below the system definition shown in Figure 2 are two branches that describe tests in still and moving air. Still-air tests represent the most basic conditions in which air can flow through an opening, and represent the conditions upon which the conventional airflow equations are based; see Figure 


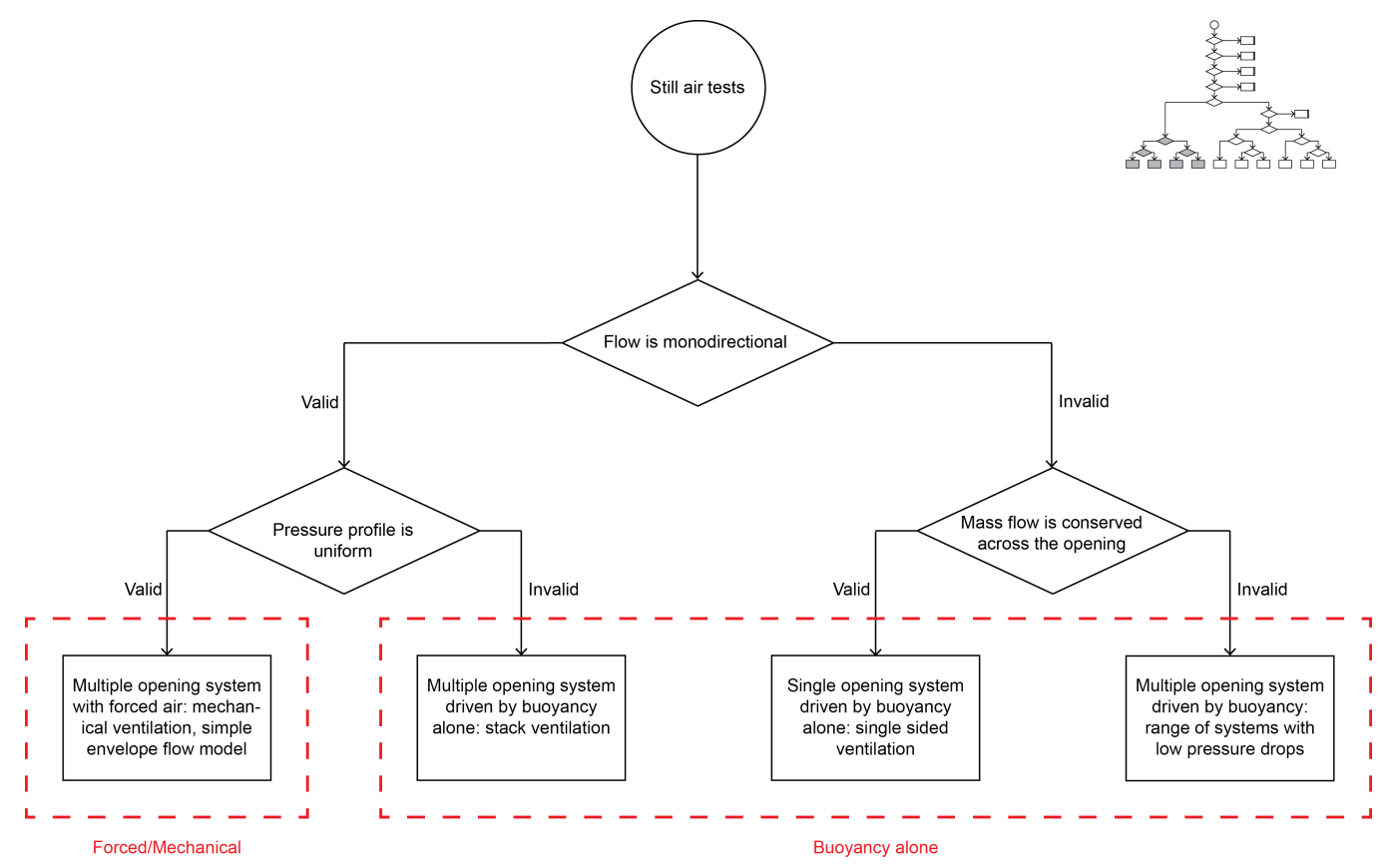

Figure 7: The assumptions that characterise still-air tests of window performance.

7. This assumes that the flow structure of the external environment is exclusively generated by airflow through the opening itself. Within this subset, flow can be conveniently divided into two types: monodirectional flow and bidirectional flow.

\subsubsection{Monodirectional flow}

Monodirectional flow is traditionally one of the simpler conditions to calculate. It represents stack or wind-driven ventilation where each opening acts exclusively as an inlet or an outlet.

2.2.1.1. Uniform pressure profile. The assumption that the pressure profile across an opening is uniform allows PPOs to be treated as point openings. This is the simplest set of conditions required for evaluating flow through an 
opening, and is a key modelling assumption of the orifice flow equation [38]. These conditions represent forced or mechanical ventilation very well, but they do not completely represent any real operating conditions of a naturally ventilated building. It represents wind-driven conditions only when the wind can be considered to be stationary at the building surface (well approximated in the stagnation zone or in the lee of the building), and buoyancy conditions when the neutral height is located an infinite distance from the opening. However, it does represent some of the basic aerodynamic properties of an opening upon which the effects of other factors can be analysed. For many operating conditions it is likely to be a reasonable approximation of real behaviour $[12,7]$.

Still-air tests that characterise airflow under these conditions are commonly used to determine the performance of components used in mechanical ventilation systems, but are not common for natural ventilation openings. This is partly because the larger dimensions of these openings require impractically large testing rigs, and the low pressures associated with natural ventilation are hard to measure. These issues can be addressed to some extent using scale models [7]. Still-air tests characterising the performance of real opening geometries are summarised in Section 2.1.1.

2.2.1.2. Non-uniform pressure profile. A difference in density between internal and external air results in a non-uniform pressure profile across its height [3]. The uniformity of the pressure profile decreases as the neutral height approaches the window height, increasing the impact of this factor. For these cases, the area distribution of the window is expected to have increased importance. 
Heiselberg et al. [38] present data for side hung windows suggesting the discharge coefficient of an opening decreases when the temperature difference creates a non-uniform pressure profile. This is characterised by graphs relating the measured discharge coefficient to a dimensionalised form of the Archimedes number, given by

$$
A r^{\prime}=\frac{\Delta T}{1000 Q^{2}}
$$

where $\Delta T$ is the temperature difference across the opening, and $Q$ is the volume flow rate through the opening. The presented data is specific to the window geometry, opening angle, wall detail, and scale used in the experiment, and therefore cannot be generalised to make performance predictions for design.

Section 5 develops an analytical approach to describing this reduction in discharge coefficient, and describes novel dimensionless parameters that characterise this effect. The predictions of this model are compared against the literature data in Section 5.1.

\subsubsection{Bidirectional flow}

Bidirectional flow is more complex than monodirectional flow. It is usually used to describe the ventilation of rooms with a single opening, but can also occur when multiple openings are located at similar heights within a façade or are substantially different in size. In still air, this represents the buoyancy alone case.

2.2.2.1. Mass conservation. The most common assumption is that of mass conservation across the opening - often simplified to volume conservation. 
This flow pattern occurs where there is a single opening in a sealed room. Bidirectional flow relies on a non-uniform pressure field to drive flow across the opening, and so the distribution of the opening area is of great importance.

A theoretical evaluation of single opening, buoyancy driven ventilation through a simple rectangular orifice can be made by integrating the orifice flow equation over the height of the opening [10]. The pressure difference is taken as a function of height, assuming that the neutral height occurs at the centre of the opening. This results in the flow equation

$$
Q=\frac{1}{3} C_{d} A_{f} \sqrt{\frac{\Delta \rho}{\rho} g h}
$$

Several studies attempt to characterise buoyancy driven, single opening ventilation through real windows. The experimental studies of side hung and centre pivot windows of Warren and Parkins [35] present graphs of correction factors to the theoretical airflow rate derived for a rectangular orifice as a function of opening angle. This allows practitioners to account for the geometry of these types of windows in a simple, unambiguous way. Compared to analytical models, the impact of the height to width ratio is negligible. Von Grabe et al. [34, 49] conduct similar experiments on a range of different opening types, characterising the change in their performance as they open. However, the performance curves are based on a potentially ambiguous free area model, which could lead to application errors. The authors introduce the idea of the thermal height of the window, providing a convincing analytical explanation for the difference in the performance of different window types. Their data suggests that air-flow rates through horizontal pivot windows, 
double sliding sash windows and side hung windows increase rapidly as the window is opened, suggesting they are useful for summer overheating or purge ventilation [42]. In contrast, air-flow rates through top and bottom hung windows increase more slowly as the window is opened, offering a greater degree of control that may be more useful when ventilating for indoor air quality in the winter [42].

Wilson and Kiel [40] identify that the ventilation rate depends on the degree of interfacial mixing between the inflow and outflow streams. ASHRAE present an equation for predicting the discharge coefficient due to this effect as a function of the temperature difference across the opening $\Delta T[10]$, given by

$$
C_{d}=0.4+0.0045 \Delta T
$$

The mixing effect is reduced at high temperature differences, and increased by local atmospheric turbulence [40]. This suggests that experiments performed in still-air could overestimate the pollutant removal rate an opening provides when installed in a turbulent environment. It is unclear how the choice of opening type affects the degree of interfacial mixing.

2.2.2.2. Unbalanced flow. Where mass flow is not conserved across an opening, flow patterns are more complex, and the system requires one or more additional airflow paths. This scenario commonly occurs where mechanical extract is used in conjunction with single sided ventilation (in bathrooms or kitchens), or where windows of different sizes are open simultaneously. Studies need to characterise both inflow and outflow rates as the neutral height is 
varied across the opening. To the best of our knowledge, there is no research into the performance of real windows under this regime, either in-situ or in controlled conditions. Airflow network models, such as CONTAM [50], apply theoretical models to describe this kind of flow through simple 2D openings. To do this, the orifice equation is integrated over the height of the opening, and the neutral height is varied until mass flow conservation is achieved. A similar approach is used by Jones et al. to model infiltration in the presence of mechanical extract [51].

\subsection{Performance in moving air}

When the wind drives flow, the air proximate to the external surface of an opening can be expected to be in motion for the majority of cases. Moving air tests can be used to investigate both the impact of wind alone, and of wind and buoyancy combined. The analytical framework shown in Figure 8 breaks down the flow configurations accordingly, which are then subdivided into monodirectional and bidirectional flow. For convenience, the impact of non-uniform wind pressures has been given as a separate factor that can be applied to flows driven by wind alone and those driven by wind and buoyancy combined.

In many cases the aerodynamic properties measured in the presence of wind may be similar to those measured in still-air tests, but significant differences are also possible. The presence of external air movement can alter the shape and directions of streamlines passing through the opening, and projecting opening geometries can interact with external flows to alter the pressure field near the surface of the opening; see Figure 9. Venturi ventilators have been used to ensure suction pressures over outlets, with pressure 
coefficients as low as -1 being achieved [15, 42] Here, pressure coefficients derived from bluff bodies will not be suitable for use with real window geometries. This interaction also affects the surface pressures for some distance around the opening, introducing additional uncertainties if other openings are present [52]. Surface pressures and flow patterns are also sensitive to the presence of buildings and trees in the immediate environment [53], meaning environmental conditions can diverge from those evaluated using simple design techniques. In addition to this, the turbulent flow structures and other unsteady behaviour associated with atmospheric wind have been proposed as another mechanism for driving ventilation $[35,7,14]$. However, unsteady flows are not readily compatible with envelope flow models, and are beyond the scope of this paper.

\subsubsection{Impact of non-uniform wind pressures}

It is commonly assumed that wind pressures acting on an opening are uniform across its surface. While this assumption is largely valid for small openings, many authors state that it is likely to break down when the openings are very large compared to the area of the façade $[4,7]$. This occurs because the pressure coefficients vary across a façade as a function of building geometry and wind angle. It is thought that this variation could become the dominant driving force behind ventilation in some configurations, but could also reduce ventilation rates by the same mechanism described for thermal buoyancy; see Section 2.2.1.2.

Non-uniform pressure profiles also occur due to interactions with complex opening geometry. Iqbal et al. [52] find that airflow passing over a centre pivot window can generate variations in static pressure across its surface 


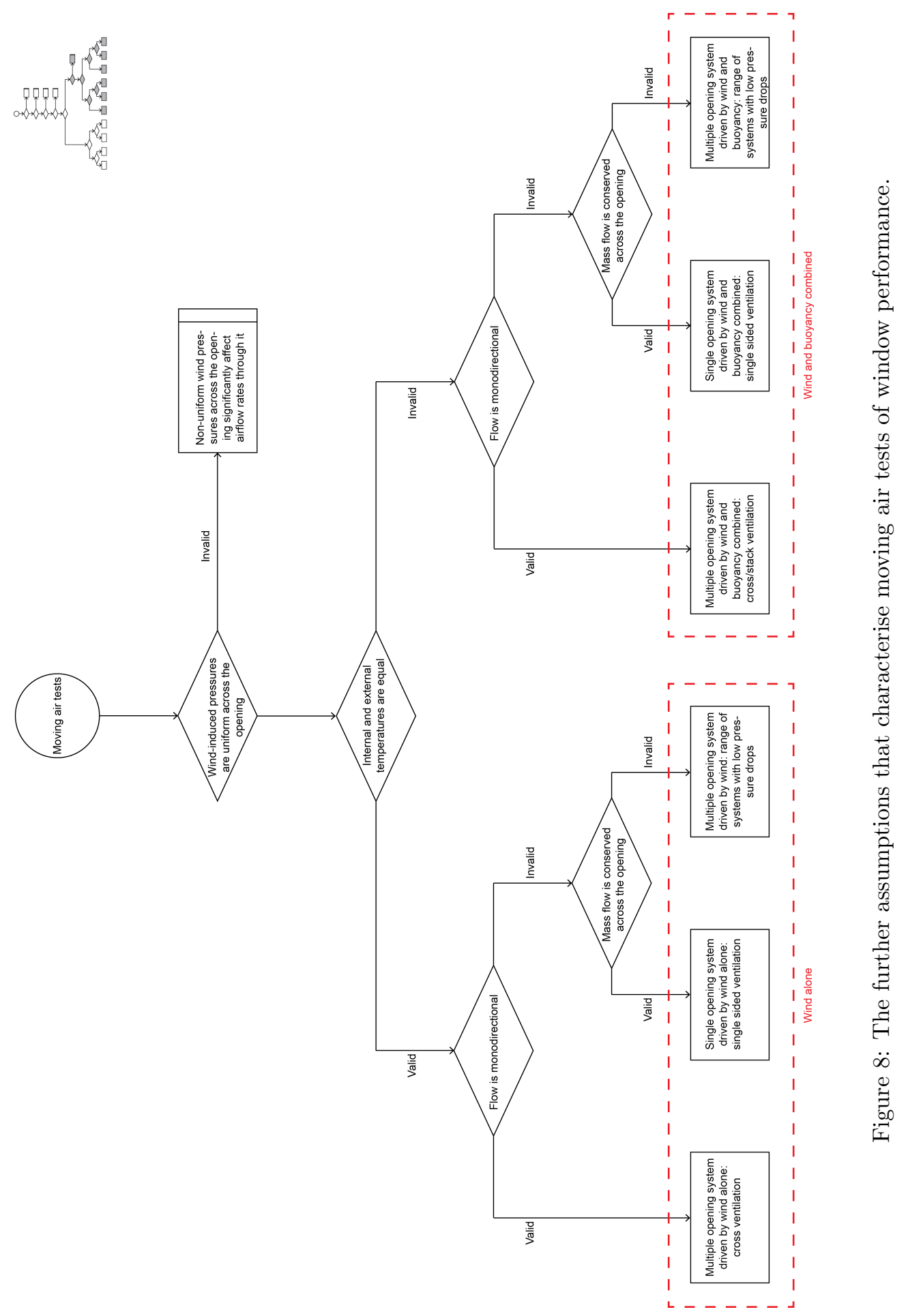



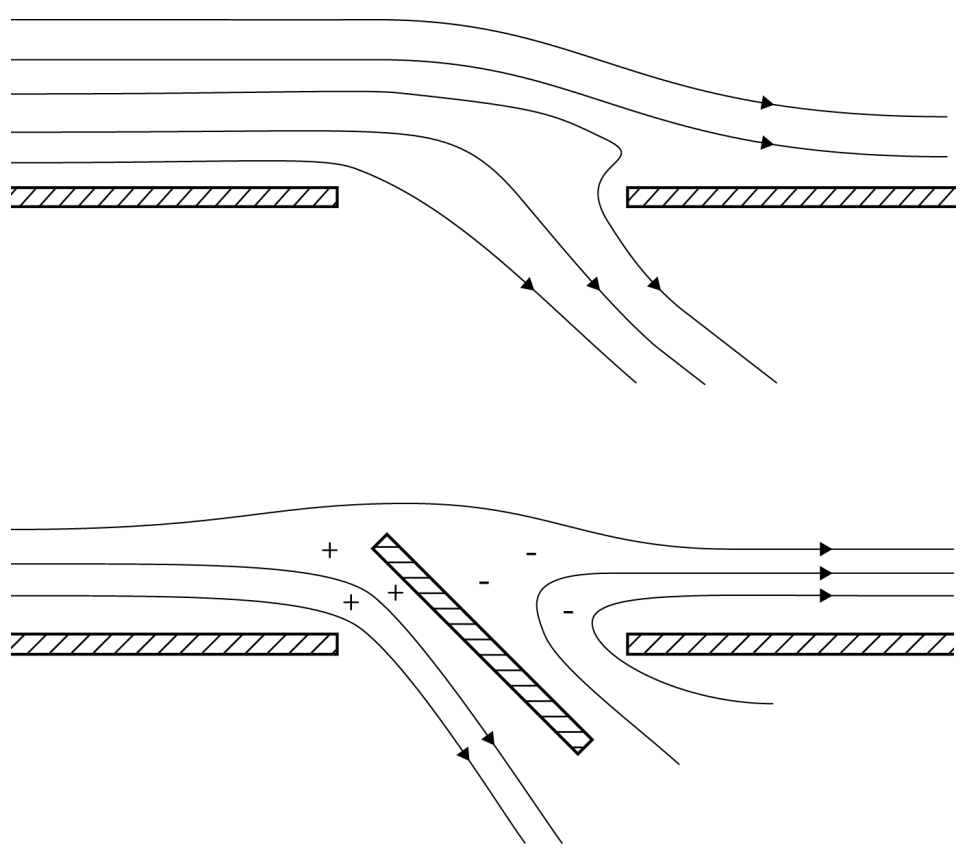

Figure 9: Diagram of the effect projecting opening geometry can have on flow patterns.

that are sufficient to drive steady-state bidirectional flow; see Figure 9. Air enters at the windward side of the opening, and leaves via the leeward side.

To the best of our knowledge there is no research studying the interaction between non-uniform wind pressures and the non-uniform pressures generated by thermal buoyancy.

\subsubsection{Internal and external temperatures are equal}

A common simplification of wind-driven flow is that the internal and external temperatures are equal. This represents wind alone conditions, where there is no contribution of buoyancy to ventilation rates. Although these conditions may only occur transiently in operation, this greatly simplifies the experimental treatment of the impact of external wind on PPOs. In 
many cases, the behaviour of an opening exposed to wind alone is expected to be a reasonable approximation for its behaviour in the presence of wind and buoyancy forces combined.

2.3.2.1. Monodirectional flow. Envelope flow models commonly assume that airflow through an opening is driven by the static pressure at the building's surface, and the dynamic pressure makes no contribution to airflow rates. However, Vickery and Karakatsanis [12] find that the orifice flow equation systematically overestimates flow rates in the presence of external wind, and the error increases as the wind angle normal to the façade increases.

The influence of external wind can be investigated analytically by considering airflow along a streamline as it enters a building; see Figure 10. It is assumed that the wind induces air motion parallel to the building surface, and that this air stream acts as the source of air that passes through the opening $[12,35,54]$. Balancing total pressures along the streamline results in an equation for airflow rate through the opening [7].

$$
Q=C_{d} A_{f} \sqrt{\frac{2\left(\Delta P+\frac{1}{2} \rho U_{L}^{2}\right)}{\rho}}
$$

where $U_{L}$ is the local wind speed parallel to the opening. This is different from the orifice flow equation, and considers the contribution of dynamic pressure to airflow through the opening. One would expect the discharge co-efficient defined using Equation 9 to be highly dependent on $U_{L}$, as any conserved momentum in the cross flow acts to reduce the minimum area through which the air passes. The influence of this on mass flow rates will, to some extent, be balanced by the increased velocity of the flow owing to 


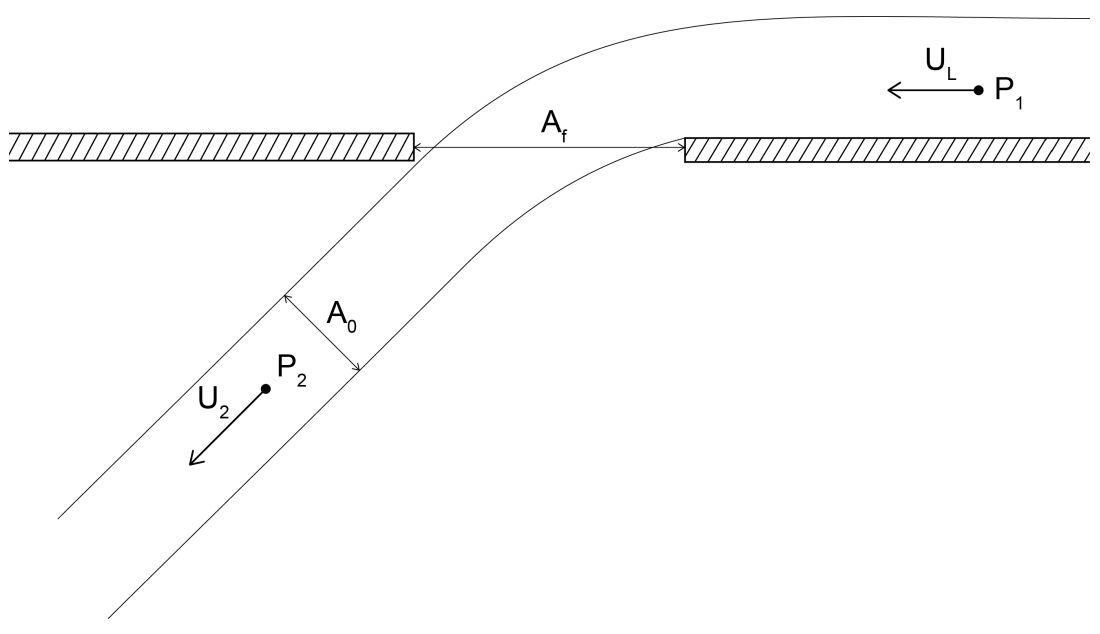

Figure 10: Diagram depicting wind induced flow through an orifice

the dynamic pressure term.

The influence of wind has been observed to cause a substantial reduction in the discharge coefficient calculated using the orifice flow equation, even for sharp edged orifices [23, 4, 55]. Kurabuchi et al. [54] and Obha et al. [55] characterise this behaviour experimentally using a dimensionless pressure coefficient defined as the ratio of the static pressure difference acting across the opening to the dynamic pressure in the external flow. The data is presented both graphically and through the use of an approximate curve fit, allowing the influence of wind on discharge coefficient to be integrated into simple computational models. Applying this data to envelope flow models can greatly reduce their error, but requires extensive data sets if the method is to be implemented to characterise the full range of real window geometries.

External air motion can interact in a range of interesting ways with real opening geometries. Kurabuchi et al. [54] identify some cases where discharge coefficients rise dramatically as the dynamic pressure in the wind becomes 
large when compared to the static driving pressures. Etheridge [7] also identifies discharge coefficients for wind cowls rising towards infinity as the wind velocity becomes very large. This may be caused by the opening interacting with external wind flows to evolve static pressure at the opening surface. They demonstrate how a characterisation of this effect can be significantly improved using Equation 9, which integrates the dynamic pressure of the external wind into the orifice equation.

2.3.2.2. Bidirectional flow. Bidirectional flow driven by wind is complex. Several different mechanisms are proposed, and the volume flow rate calculations used in practice are based on simple empirical correlations. The correlations given in the CIBSE Guides and Manuals [3, 8], and the European standard EN16798-7:2017 [56], are limited to fully open windows, where mass flow is conserved across the opening. They also take no account of the impact of wind direction.

The bidirectional flow ventilation calculations presented in CIBSE Guide A are based on the research of Warren and Parkins [35], who recommend calculating the effects of wind and buoyancy separately, and then taking the larger value. For wind-driven ventilation, they model mixing across the boundary of an opening due to the turbulent shear layer that forms when moving air passes a region of stationary flow. A simple empirical correlation with reference wind speed is given to characterise a minimum flow rate to be used for the sizing of openings. They also present data describing how the flow rate changes for different turbulence scales and graphs of corrections for side hung windows as they open and close. Ventilation rates are characterised using a non-dimensional flow number $F_{L}$, defined using the velocity of the flow at the 
building's surface. When applied to real buildings, this requires the distribution of wind velocities on a building's surface to be known. Kurabuchi et al. [54] describe simple wind tunnel techniques for measuring and presenting dynamic pressure distributions, but not their direction.

An alternative transient method of wind-driven bidirectional proposed is pulsation theory [57]. Where room volumes are large, significant volumes of air can be driven into a space by fluctuating pressures at an opening, without significantly pressurising the space. This leads to ventilation rates that are dependent on the volume of the internal space, and the magnitude and frequency of external pressure fluctuations. The use of their calculation methodology is inhibited by a lack of available design data.

The data presented by Warren and Parkins [35] is not widely available, but could be of immediate practical use to designers. More recent attempts to model more complex flow mechanisms [58] and a range of opening geometries [59] do not improve on the model presented by Warren and Parkins [35], as they have errors of a similar magnitude that do not justify the increased model complexity.

2.3.2.3. Multiple openings. Much of the literature that underpins best-practice standards assumes that ventilation systems comprising multiple openings on a single wall can be adequately described by treating each opening in isolation. However, there is evidence that when multiple openings exist on a façade, mass flow rates can be greater than those predicted by the single opening equations $[35,21,14]$. This is primarily due to differing local pressure coefficients between any two openings driving flow. Here, mass flow rates cannot be said to be conserved through each window, and surface av- 
eraged pressure coefficients cannot justifiably be used. This might simplify the flow through the opening to the monodirectional flow case, but it is also possible that bidirectional mechanisms occur where differential pressures are sufficiently small [8].

\subsubsection{Wind and buoyancy combined}

Sections 2.2.1.2 and 2.2.2.1 show that the uneven pressure profile associated with a temperature difference across an opening can both decrease monodirectional flow rates and increase bidirectional flow rates. To the best of our knowledge there is no research studying wind-driven monodirectional flow in the presence of buoyancy forces, or how this may impact predictions of volume flow rates. However, the internal flows generated by wind forces exceed those due to thermal buoyancy, even in light winds [12]. This suggests the influence of buoyancy on the aerodynamic properties of an opening in the presence of wind may be small.

2.3.3.1. Bidirectional flow. The European standard used to predict ventilation rates through single openings [56] is based on the correlations of De Gids and Phaff [60], which seek to account for the effect of wind and buoyancy combined. The simplified equations they produced are used as the basis for further research by Larsen and Heiselberg [20], who account for the wind direction to reduce the error in the model from $29 \%$ to $23 \%$. However, the use of this equation requires information about the variation in wind pressure across the surface of the opening - which will vary with building geometry, opening location and wind direction - making it of less practical use in the early design of a naturally ventilated building. 


\begin{tabular}{l|c|l}
$\begin{array}{l}\text { Environmental conditions } \\
\text { flow configuration }\end{array}$ & Predictive equations & Source \\
\hline $\begin{array}{l}\text { Still-air, monodirectional, uniform } \\
\text { pressure profile [Forced air, } \\
\text { multiple opening] }\end{array}$ & $Q=C_{d} A \sqrt{\frac{2 \Delta P}{\rho}}$ & $\begin{array}{l}\text { ASHRAE Fundamentals [10], } \\
\text { CIBSE Guides A and AM10 [8, 3], } \\
\text { CONTAM [50] } \\
\text { Etheridge [7], Bailey et al. [44] } \\
\text { CONTAM [50], Sherman [45] }\end{array}$ \\
$\begin{array}{l}C_{d}=f(R e) \\
Q=C \Delta P^{n}\end{array}$ &
\end{tabular}

Table 1: Predictive equations under conditions for forced ventilation - often used to describe monodirectional flow under any driving force.

While the predictive equations used in practice assume the forces of buoyancy and wind act constructively, Caciolo et al. [28] identify cases where the interaction of wind reduces the ventilation rate expected from buoyancy alone. This reinforces the measurements of Kiel and Wilson [40], who show that interfacial mixing by the wind can reduce ventilation efficiency.

\subsection{Extent of knowledge}

The framework set out in Sections $2.1-2.3$ breaks down a range of characteristic environmental conditions that drive flow through PPOs and the range of flow structures that can occur within these openings. As the mechanisms vary, so do the equations that describe flow through them. A range of equations given in the literature to describe these flow scenarios are given in Tables $1-4$.

In principle, each flow scenario needs to be characterised with its own testing regime, and the degree to which it can be described using stillair discharge coefficients assessed. In practice this is very rarely achieved. EN 13141-1 standardises still-air pressurisation tests of PPOs [17], but this does not require parametisation that would enable modeling under a range of ventilation pressures. Similarly, European technical standards specify testing regimes for roof outlets in the presence of wind [62,43], but these do 


\begin{tabular}{|c|c|c|}
\hline $\begin{array}{l}\text { Environmental conditions / } \\
\text { flow configuration }\end{array}$ & Predictive equations & Source \\
\hline $\begin{array}{l}\text { Still-air, monodirectional, } \\
\text { non-uniform pressure profile } \\
\text { [buoyancy alone, multiple } \\
\text { opening] }\end{array}$ & $\begin{array}{c}Q=C_{q} C_{d} A \sqrt{\frac{2 \Delta P}{\rho}} \\
\text { where } C_{q}=f\left(\frac{2 \Delta P}{\Delta \rho g h}\right)\end{array}$ & $\begin{array}{l}\text { Proposed in this paper; see Sec- } \\
\text { tion } 5\end{array}$ \\
\hline $\begin{array}{l}\text { Still-air, bidirectional, } \\
\text { flow-conservation [buoyancy } \\
\text { alone, single opening] }\end{array}$ & $\begin{array}{c}Q=\frac{1}{3} C_{d} A \sqrt{\frac{\Delta \rho}{\rho} g h} \\
\text { where } \frac{\Delta \rho}{\rho}=\frac{\Delta T}{T} \\
\text { and } C d=0.4+0.0045 \Delta T\end{array}$ & $\begin{array}{l}\text { Warren and Parkins [35], } \\
\text { ASHRAE Fundamentals [10], } \\
\text { CIBSE guides A and AM10 } \\
{[8,3]} \\
\\
\text { ASHRAE Fundamentals [10], } \\
\text { Wilson and Kiel [40] }\end{array}$ \\
\hline $\begin{array}{l}\text { Still-air, bidirectional, unbal- } \\
\text { anced flow [buoyancy alone, } \\
\text { multiple opening] }\end{array}$ & $\begin{aligned} Q_{\text {out }} & =w C_{d} \int_{z_{n}}^{h_{T}} \sqrt{2 \Delta P(z) d z} \\
Q_{\text {in }} & =w C_{d} \int_{h_{B}}^{z_{n}} \sqrt{\Delta P(z) d z}\end{aligned}$ & CONTAM [50] \\
\hline
\end{tabular}

Table 2: Predictive equations for buoyancy only ventilation

\begin{tabular}{l|c|l}
$\begin{array}{l}\text { Environmental conditions } \\
\text { / flow configuration }\end{array}$ & Predictive equations & Source \\
\hline $\begin{array}{l}\text { Moving-air, uniform } \\
\text { temperature, monodirectional } \\
\text { [Wind alone, multiple } \\
\text { opening] }\end{array}$ & $Q=C d A \sqrt{\frac{2 \Delta P}{\rho}}$ & Kurabuchi et al. \\
& where $C d=f\left(\frac{2 \Delta P}{\rho U_{L}^{2}}\right)$ & \\
& where $C d=f\left(\frac{U_{L} A}{Q}\right)$ & $\begin{array}{l}\text { Etheridge [7], Chiu and } \\
\text { Etheridge [23] }\end{array}$ \\
$\begin{array}{l}\text { Moving-air, uniform } \\
\text { temperature, bidirectional, } \\
\text { flow conservation [wind alone, } \\
\text { single opening] }\end{array}$ & $Q=0.025 A U_{R}$ & $\begin{array}{l}\text { CIBSE guides A and AM10 [8, } \\
\text { 3], Warren and Parkins [35] } \\
\text { Warren and Parkins [35] }\end{array}$ \\
$\begin{array}{l}\text { Moving-air, uniform temper- } \\
\text { ature, bidirectional, unbal- } \\
\text { anced flow [Wind alone, mul- } \\
\text { tiple opening] }\end{array}$ & $Q=A^{*} U_{R} \sqrt{0.32 \Delta C_{p}+0.09 \sigma_{\Delta C_{P}}}$ & Daish et al. [14] \\
\hline
\end{tabular}

Table 3: Predictive equations for wind alone ventilation 


\begin{tabular}{|c|c|c|}
\hline $\begin{array}{l}\text { Environmental conditions } \\
\text { / flow configuration }\end{array}$ & Predictive equations & Source \\
\hline $\begin{array}{l}\text { Moving air, temperature dif- } \\
\text { ference, mono-directional flow } \\
\text { [Wind and buoyancy com- } \\
\text { bined, multiple openings] }\end{array}$ & - & - \\
\hline $\begin{array}{l}\text { Moving air, temperature } \\
\text { difference, bidirectional flow, } \\
\text { flow conservation [Wind and } \\
\text { Buoyancy combined, single } \\
\text { opening] }\end{array}$ & $\begin{array}{c}Q=\frac{1}{2} C_{d} A \sqrt{C_{1} U_{10}^{2}+C_{2} h \Delta T+C_{3}} \\
Q=\frac{1}{2} C_{d} A \sqrt{\max \left(C_{1} U_{10}^{2} ; C_{2} h \Delta T\right)} \\
Q=A \sqrt{a \Delta T+b U_{R}^{2}}\end{array}$ & $\begin{array}{l}\text { De Gids and Phaff [60], } \\
\text { BS EN 15242:2007 [61] } \\
\text { BS EN 16798-7:2017 [56] } \\
\text { ASHRAE Fundamentals [10] }\end{array}$ \\
\hline $\begin{array}{l}\text { Moving air, temperature } \\
\text { difference, bidirectional flow, } \\
\text { flow conservation, } \\
\text { non-uniform wind pressure } \\
\text { [Wind and Buoyancy } \\
\text { combined, single opening] }\end{array}$ & $\begin{array}{c}Q=A \sqrt{C_{U}+C_{T}+C_{\Delta P}} \\
C_{U}=C_{1}\left|C_{P}\right| U_{R}^{2} \\
C_{T}=C_{2} h \Delta T \\
C_{\Delta P}=C_{3} \Delta C_{P(\text { opening })} \frac{\Delta T}{U_{R}^{2}}\end{array}$ & Larsen and Heiselberg [20] \\
\hline $\begin{array}{l}\text { Moving air, temperature dif- } \\
\text { ference, bidirectional flow, } \\
\text { unbalanced flow [Wind and } \\
\text { Buoyancy combined, multiple } \\
\text { openings] }\end{array}$ & - & - \\
\hline
\end{tabular}

Table 4: Predictive equations for wind and buoyancy combined ventilation

not yield parameters suitable for modelling. No similar standard is found for inflow openings, or for openings in walls.

Standardised test methods to evaluate the aerodynamic properties of PPOs are largely absent for a range of driving mechanisms. As a result, data sets provided by manufacturers cannot confidently be applied for a range of design conditions. However, there is scope within the existing literature to derive such tests. The experimental procedures of Warren and Parkins [35] could be used as the basis for standardised tests for buoyancy driven and wind driven bidirectional flows through PPOs in the single opening configuration. Similarly, the procedures developed by kurabuchi et al. could be used to standardise performance tests of monodirectional flow in the presence of wind. For many categories of experimental conditions identified within the framework, academic research does not yet provide adequate procedures to 
evaluate the aerodynamic performance of specific PPOs; see Sections 2.1.3, 2.1.4, 2.2.2.2, 2.3.1, 2.3.2.3, and 2.3.3.

The use of sharp-edged, flush orifices are ubiquitous in investigations of ventilation phenomena, but academic data characterising the aerodynamic performance of specific PPOs, or types of PPO, is scarce. Data is available for still-air discharge coefficents of hinged openings [31, 32, 33]; buoyancy alone, single opening discharge coefficients for side hung and horizontal pivot openings [35]; and wind alone, single opening discharge coefficients for hinged openings [35]. Predictive equations describing still-air performance for airflow through insect mesh [44], and combinations of mesh and louvres [42] are available in the literature. This study identifies no sufficiently comprehensive data sets for other opening types or flow configurations.

\section{Statistical Effective Area Model}

To address the failings of free area models discussed in Section 2.1.1, a Statistical Effective Area Model (SEAM) has been created. This model is based on that proposed in BB101 [41], and fit using academic data for hinged openings [31, 32, 33]. The discharge coefficient is defined according to Equation 5, and described for a constant aspect ratio by

$$
C_{d}(\theta)=B\left(1-e^{-M \theta}\right)
$$

where $B$ and $M$ are coefficients that can be fit to experimental data. The fitted coefficients $B$ and $M$ are plotted as a function of aspect ratio, and described by empirical correlations given by 


$$
\begin{aligned}
& B=0.18 e^{-0.78(\sigma)}+0.61 \\
& M=0.016(\sigma+1)
\end{aligned}
$$

Although this model is defined for top or bottom hung openings, rotational symmetry enables the same model to be used for side hung openings when the inverse aspect ratio $w: h$ is substituted.

\subsection{Comparing the performance of different area models}

To quantify the errors associated with each modelling technique, we have compared the discharge coefficients predicted by the free area models, the BB101 online calculator, and SEAM with experimental data from the literature $[31,32,33]$; see Figure 11 . This shows that that the ambiguity of free area models can lead to significant variations in predicted performance that can either under or over-estimate airflow rates. The predicted values of the discharge coefficient are calculated using Equation 4 for the range of height to width ratios and opening angles present in the literature, substituting the effective areas predicted using each modelling technique. The effective area predicted by the free area models are calculated using a discharge coefficient of 0.61 , although 0.65 is also common [10].

The difference between model predictions and experimental data comes from systematic error caused by a poorly fitting model and random error in the experimental data. These errors can be combined to assess the confidence in each model when used to predict the aerodynamic performance of an opening. 


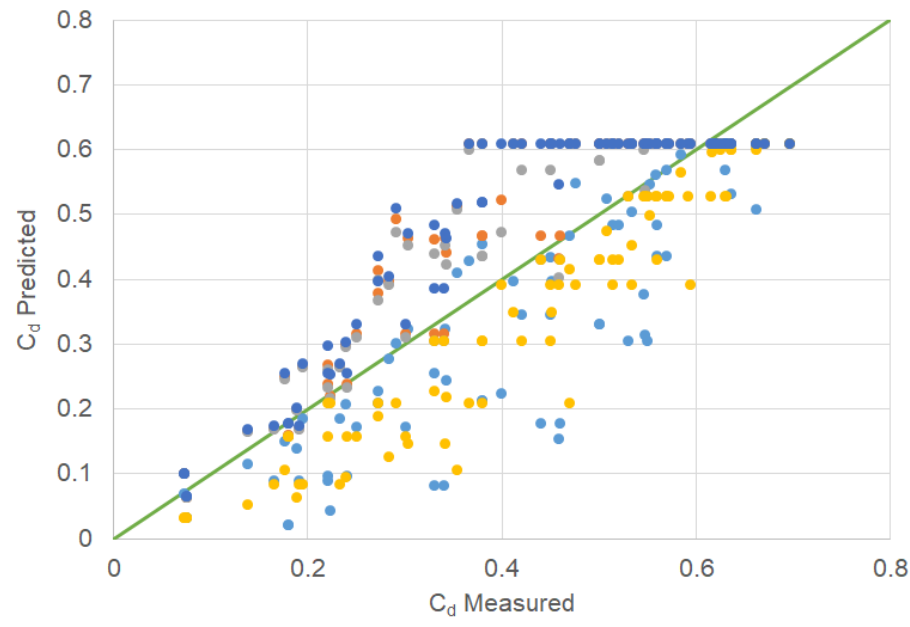

- model a) ( $\alpha=23 \%$ )

- model b) ( $\alpha=17 \%)$

- model c) ( $\alpha=15 \%)$

- model d) ( $\alpha=25 \%)$

- model e) ( $\alpha=21 \%$ )

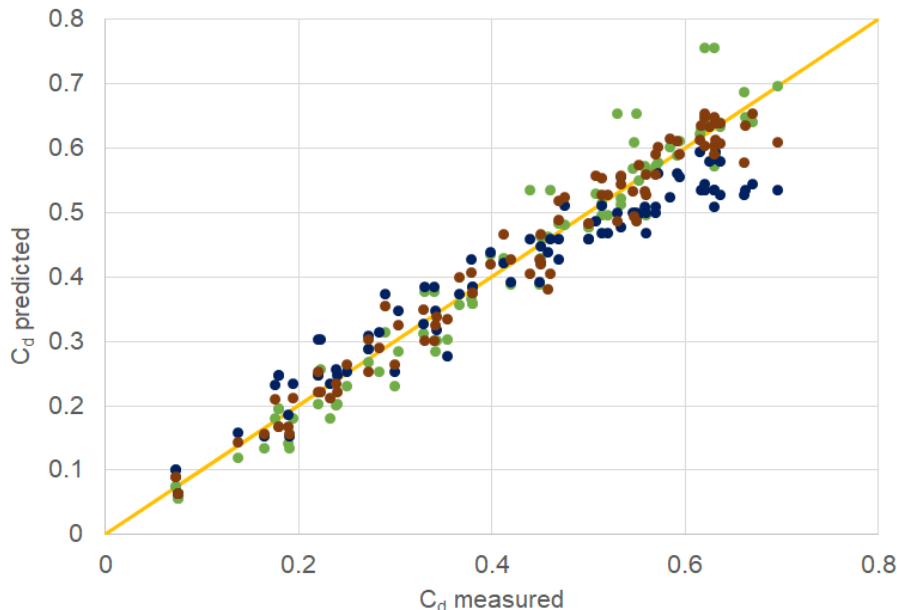

- model f) ( $\alpha=2.5 \%$ )

- BB101 calculator ( $\alpha=2.6 \%)$

- SEAM ( $\alpha=1.2 \%$ )

Figure 11: Relationship between predicted and measured values of the discharge coefficient (as defined in Figure 6) for a range of predictive models and their standard error, $\alpha$.

Top, purely analytical free area models; Bottom, semi-empirical models (see Figure 5 for descriptions). 
If the deviation from the model is entirely random there is an equal chance of deviations occurring above or below the model predictions, and therefore the mean deviation would be zero. The mean systematic error can therefore be estimated from the mean deviation. It must be stressed that this is a mean systematic error, and a model that overestimates in some regions and underestimates in others may have an artificially low mean systematic error. This is to some extent compensated for by an increase in random error. Some height to width ratios and opening angles result in greater systematic errors than others, which can be as large as $80 \%$. In addition, while the percentage deviation between model and data is normally distributed for the quasi-empirical models, this is not true for the purely analytical models.

The model proposed in this paper - SEAM - fits the data the best, and can predict opening performance with a standard error of 1.2\%. Free area model $d$ is used in the safety-critical application of smoke ventilation, and is the only model that systematically underestimates aerodynamic performance. This will result in the specification of openings that outperform design predictions, and therefore the model does not need updating urgently. SEAM will be included in an updated BB101 calculator. The model is based on data from large openings where $t / h<<1$ (see Figure 6), so an analytical model based on geometric similarity of the free area has been included in the calculator for smaller or thicker openings where the opening thickness cannot be neglected. This analysis shows that purely analytical free area models cannot be applied with confidence to predict the aerodynamic performance of PPOs. Predictive models created to support system design must be calibrated with empirical data for the range of geometric parameters within which it will be 

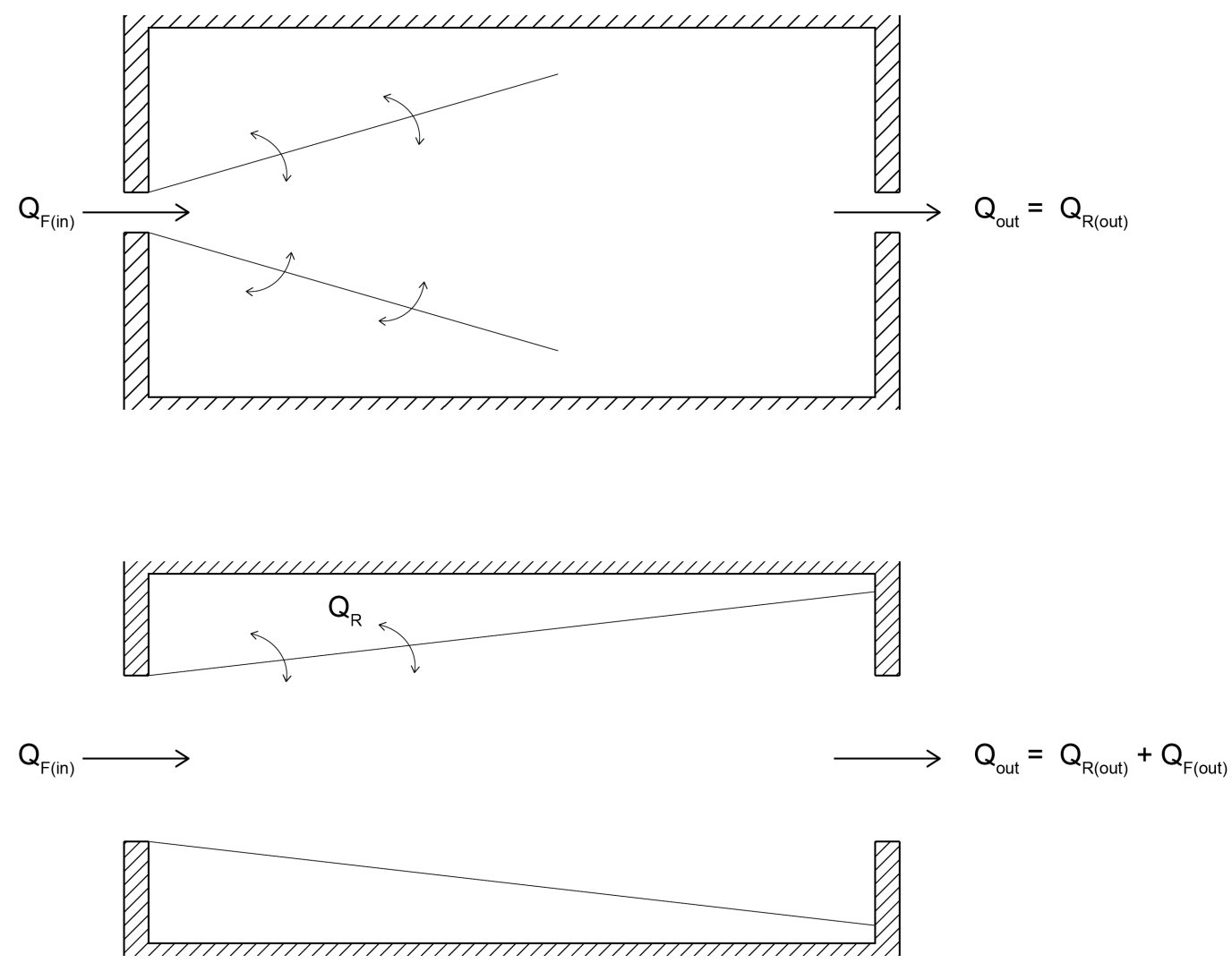

Figure 12: An illustration of the difference between an expanding jet from a small opening (top) and a large opening (bottom).

applied.

\section{Modelling the impact of flow connection}

Section 2.1.4 identified evidence of increases in bulk airflow rate that occur when inflow and outflow openings are closely aligned. This effect may be caused by conservation of kinetic energy between the inflow jet, or it may be associated with a change in streamline shape in the approach to the outlet. Moreover, it is unclear whether this effect is beneficial, as it is possible that 
this flow connection inhibits the removal of pollutants from the wider space.

We have developed a simplified analytical approach to this question by looking at the stream tube formed between two aligned openings in a large space; see Figure 12. In this model, we treat the inflow air as a free jet, which expands as it entrains air on its journey towards an outlet located on the opposite wall. When the inlet is small, the inflow jet mixes thoroughly with the room air before being extracted and so the extracted air can be considered to be made up entirely of room air. The kinetic energy is also completely dissipated, resulting in still-air conditions at the surface of the outflow opening. Conversely, when the inlet is large, much of the fresh air leaves via the outlet without mixing with the room air, and the jet reaches the outlet with a significant velocity. Room air can be removed from the space only by entrainment into the jet.

The effect of flow connection on a natural ventilation strategy can be broken down into two key phenomena; the increase in bulk airflow rate due to conservation of kinetic energy and the reduction in ventilation effectiveness [8], $E_{v}$, caused by short circuiting of fresh air.

A simple model for estimating bulk airflow rates can be made using a modified envelope flow model, which allows a proportion of the dynamic pressure in the inflow jet to be conserved to drive air through the outflow opening. The dynamic pressure in the jet available to drive airflow can be evaluated using the entrainment equations for ideal free jets [19]. Assuming the discharge coefficients of the openings are unchanged by the altered streamlines, a dimensionless volume flow rate can be evaluated 


$$
\frac{Q}{Q_{E}} \sqrt{\frac{1+A^{* 2}}{1+A^{* 2}-16 \frac{A_{e f f(1)}}{x^{2}}}}
$$

where $Q_{E}$ is the volume flow rate predicted by conventional envelope flow models, $A^{*}$ is the ratio of the effective area of the inlet $A_{\text {eff(1) }}$ to the effective area of the outlet $A_{e f f(2)}$, and $x$ is the distance between the two openings.

The ventilation effectiveness [8] can be defined as the proportion of room air in the jet at the outlet. Similarly, this can be evaluated using the entrainment equations for free jets [19], giving

$$
E_{v}=\frac{Q_{R(\text { out })}}{Q_{\text {out }}}=1-4 \frac{\sqrt{A_{\text {eff }(1)}}}{x}
$$

where $Q_{R(o u t)} / Q_{\text {out }}$ is the proportion of room air extracted from the space. The effective ventilation rate of room air can be calculated as the product of the ventilation effectiveness and the volume flow rate. Equations 13 and 14 suggest that the relevant dimensionless parameter is the ratio $\sqrt{A_{e f f}} / x$, rather than the commonly favoured opening porosity [4].

\subsection{Comparison with literature data}

The predictions of these equations can be compared against the data presented by Seifert et al. [48]. They present a CFD study of a $6 m$ cube, where the area of the inlet and outlet are gradually increased. By applying the model to this data, the mass flow rate of room and fresh air can be plotted as opening area is increased; see Figure 13. Once flow connection has been formed, the rate at which room air is removed drops and is not sufficiently offset by increasing flow rate of fresh air. This contrasts with conventional wisdom that larger airflow rates imply higher pollutant dilution 


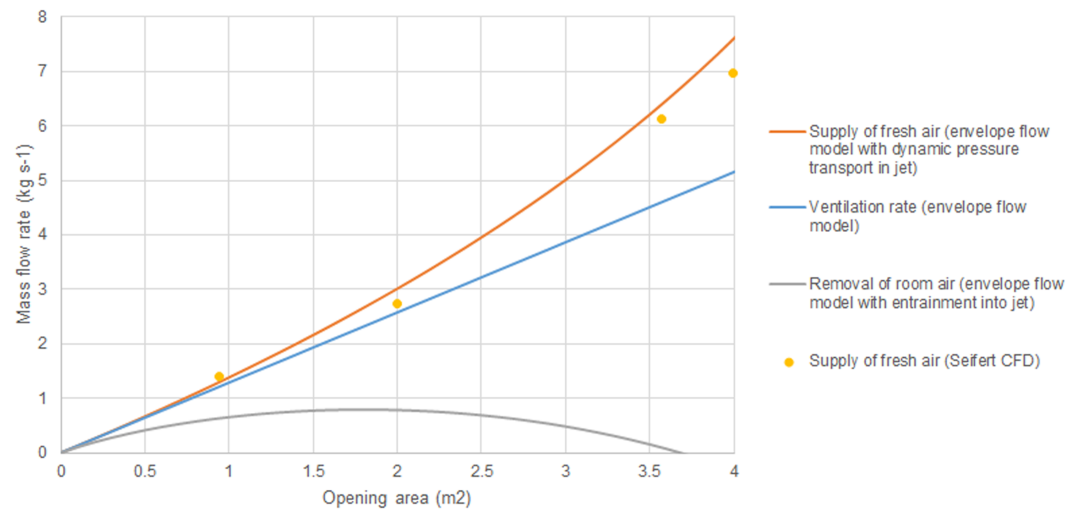

Figure 13: The predicted ventilation rate of room air has been plotted alongside CFD data presented by Seifert [48].

777

rates and provide more effective ventilative cooling. It also demonstrates the continuous predictions made by combining free jet and envelope flow models agree well with the discrete data points produced by the CFD. This suggests that the increase in volume flow rate is caused primarily by transmission of dynamic pressure in the jet, and not by a reduction in discharge coefficient. The agreement is surprising given the scale of the difference in complexity and computation time between the two models.

Counter-intuitively, this model suggests that, under certain circumstances, increasing the open area can reduce pollutant removal from a space. Ventilation strategies should be designed to prevent flow contact between the inflow jet and the outflow opening. This can either be achieved by interfering with the transmission of the jet through the space, or by manipulating the openings to adjust the size, velocity and direction of the inflow jet. These parameters represent a set of aerodynamic properties that need to be characterised for different opening types, beyond merely their resistance to airflow. 
Knowledge of these properties would be useful when designing for thermal comfort, as well as ensuring contact with thermal mass.

In real buildings, the reduction in pollutant removal rates is likely to be less severe than predicted by the model, as three-dimensional opening geometry, buoyancy, and internal obstacles will interfere with the clean propagation of the jet and encourage mixing. However, formation of a wall jet caused by locating openings near ceilings would reduce the entrainment coefficient [19], which could cause pollutant removal rates to be lower than predicted.

\section{Modelling the impact of buoyancy-induced non-uniform pres- sure profiles}

A reduction in the discharge coefficient that occurs in buoyancy driven ventilation is identified in Section 2.2.1.2. This might occur because the non-uniform pressure profile associated with a high temperature difference invalidates the point area assumption used in the orifice equation. If this is the case, it should be possible to evaluate flow rates analytically using an area profile for the opening.

Side hung windows do not have a uniform area profile, and so the paths of least resistance are at the top and bottom of the window. In order to analyse a worst case scenario, it is assumed that the measured effective area can be represented by two equal, point openings at the window's extremities; see Figure 14. Evaluating the flow through these two openings yields a correction

factor, $C_{q}$, that can be applied to the conventional orifice flow equation, where

$$
C_{q}=\frac{1}{2}\left(\sqrt{1+\frac{1}{P^{*}}}+\sqrt{1-\frac{1}{P^{*}}}\right)
$$




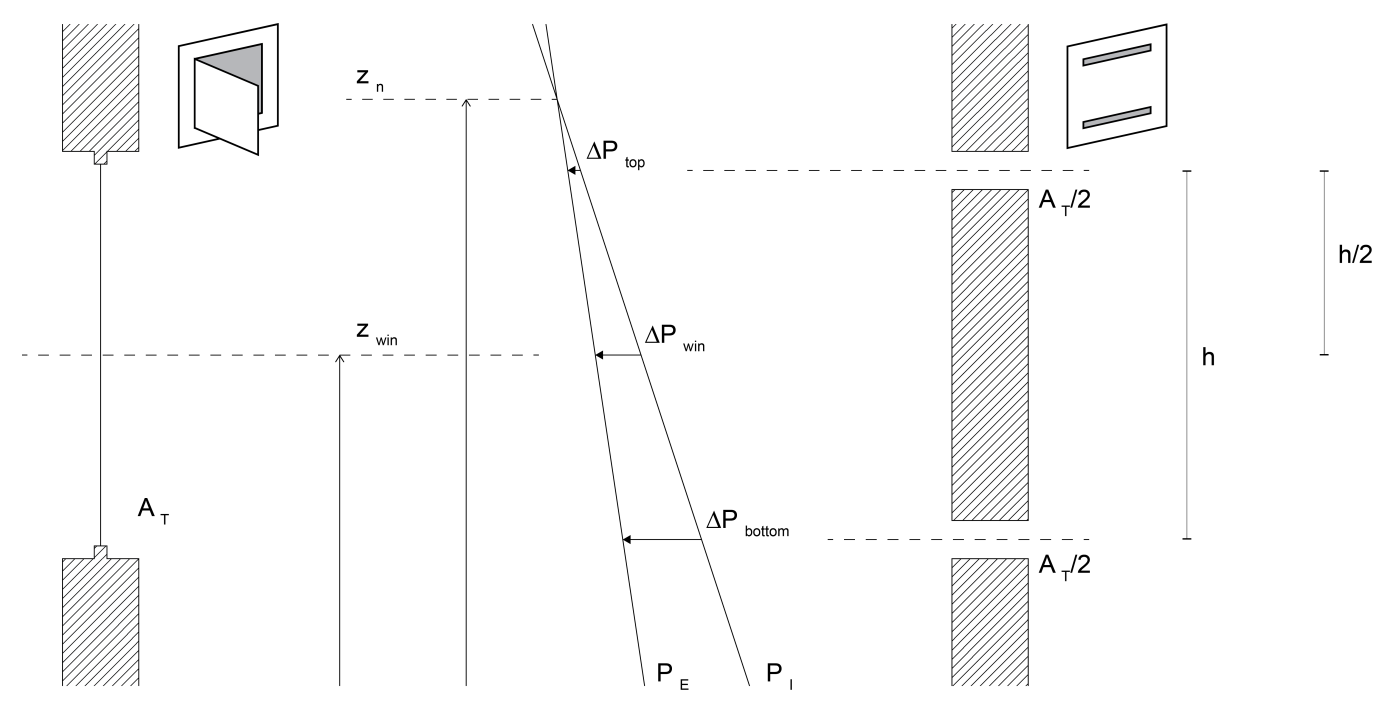

Figure 14: Diagram of a side hung window (left) against the model proposed to evaluate flow through it (right)

$$
P^{*}=\frac{2 \Delta P_{w i n}}{\Delta \rho g h}
$$

where $\Delta P_{\text {win }}$ is the measured pressure difference across the centre of the window, $\Delta \rho$ is the density difference between indoor and outdoor air and $h$ is the height of the opening; see Figure 14. Flow is monodirectional when $P^{*} \geq$ 1 or $\leq-1$, and bidirectional where $-1 \leq P^{*} \leq 1$. Still-air pressurisation tests describe behaviour where $P^{*} \rightarrow \pm \infty$.

For buoyancy only ventilation, the non-dimensional pressure can be shown to be equivalent to a non-dimensional height, $h^{*}$, which allows the correction 


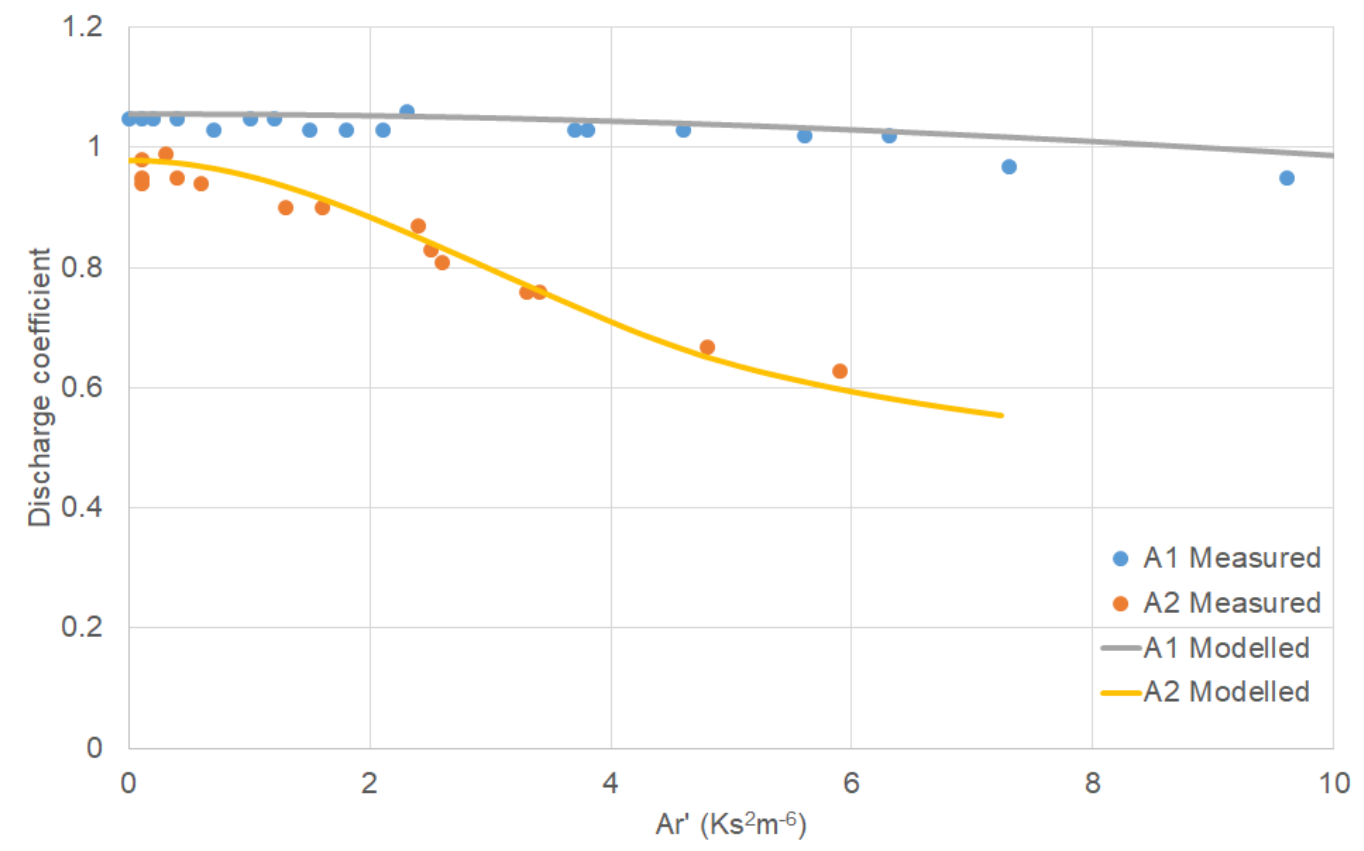

Figure 15: The analytical correction factor compared against the data measured by Heiselberg et al. [38].

factor to be described independently of the pressure across the window and the density difference;

$$
h^{*}=\frac{2\left(z_{n}-z_{w i n}\right)}{h}
$$

where $z_{n}$ is the neutral pressure height, defined as the height on the facade where the internal and external pressures are equal, and $z_{\text {win }}$ is the height of the window at its centre. Thus, the correction factor can be found in the design case by considering the building geometry alone, isolated from the environmental conditions. 


\subsection{Comparison with literature data}

To enable the analytical model to be compared with the data presented by Heiselberg et al. [38], Equations 6, 15, and 16 have been combined to describe the relationship between $C_{q}$ and $A r^{\prime}$ that can be solved by iteration.

$$
C_{q}\left(A r^{\prime}\right)=\frac{1}{2}\left(\sqrt{1+\frac{1000 C_{q}^{2} A_{e f f}^{2} A r^{\prime} g h}{T}}+\sqrt{1-\frac{1000 C_{q}^{2} A_{e f f}^{2} A r^{\prime} g h}{T}}\right)
$$

The height of the window and an estimate of the mean temperature can be found directly from the reference, and an estimate of the window's effective area can be made using the product of the discharge coefficient measured at $A r^{\prime}=0$ and the stated free area used to calculate this discharge coefficient. The predicted relationship between $A r^{\prime}$ and the discharge coefficient calculated in the reference can then be given by

$$
C_{d}\left(A r^{\prime}\right)=C_{d A r^{\prime}(0)} C_{q}\left(A r^{\prime}\right)
$$

The agreement between the analytical model and the data of Heiselberg et al. [38] is good, suggesting it can be used to predict the reduction in the discharge coefficient; see Figure 15. The model is expected to become increasingly inaccurate as the opening angle increases.

\section{Conclusions}

The analytical framework is an effective tool for defining different types of flow through openings. The use of this tool enables a clear and compre- 
hensive literature review to be made, where different studies and descriptive equations can be compared on a like-for-like basis.

The framework identifies a lack of standardised testing regimes for characterising opening performance under a range of environmental conditions. In some areas, academic research does not yet provide adequate procedures to evaluate the performance of specific PPOs.

While the use of sharp-edged rectangular orifices are ubiquitous in the investigation of ventilation phenomena, aerodynamic performance data for other types of types of PPO are scarce. Use of ambiguous free area models are commonplace, and are potentially a source of large variations in measured aerodynamic properties between papers.

The framework is used to identify three key areas where understanding can be improved by analysis of existing data: the prediction still-air performance characteristics for butt hinged openings; modelling the increase in airflow rate that occurs through two aligned openings; and modelling the reduction in discharge coefficient that occurs when a large temperature difference exists across the opening.

A Statistical Effective Area Model (SEAM) is developed from academic data to estimate the still-air performance of hinged openings in the design stage, accounting for the impact of aspect ratio and opening angle. This model predicts literature data with a standard error of $1.2 \%$, compared to a $15-25 \%$ error offered by free area models commonly used in industry. Most analytical free area models, such as that given in CIBSE AM10 [3], overestimate airflow through openings and require urgent revision. However, one model used in safety-critical smoke ventilation applications [18] system- 
atically underestimates flow rate and does not require urgent revision.

An analytical model is made based on entrainment theory to explain the increase in flow rate that occurs through two aligned openings. This model identifies the dimensionless ratio $\sqrt{A} / x$ as the characteristic parameter describing the phenomena, rather than the opening porosity commonly cited in the literature. The predictions of the analytical model match CFD predictions of airflow rate given in the literature well, and predicts a detrimental impact on pollutant removal from the wider space. The latter phenomena is not identified in the literature, and represents opportunity for further study.

Finally, an analytical model is created to explain the reduction in discharge coefficient that occurs when a large temperature difference exists across an opening. This model defines a novel dimensionless parameter that characterises the flow based on the ratio of the pressure drop across the centre of the opening to the variation in pressure due to buoyancy across its height. This can be determined in isolation from building geometry, and determines whether mono-directional or bidirectional flow is occurring through the opening. The model predicts literature data well, suggesting it can be directly integrated into design equations.

The results here suggest a range of avenues where further work may be required, and new predictive tools have been created that can be directly used to reduce design errors in the engineering of a naturally ventilated building. 


\section{7 •}

898 - 


\section{References}

[1] P. Karava, T. Stathopoulos, A. Athienitis, Wind driven flow through openings-a review of discharge coefficients, International journal of ventilation 3 (3) (2004) 255-266.

[2] B. M. Jones, M. J. Cook, S. D. Fitzgerald, C. R. Iddon, A review of ventilation opening area terminology, Energy and Buildings 118 (2016) 249-258.

[3] CIBSE, Natural ventilation in non-domestic buildings: CIBSE Applications Manual AM10, Chartered Institution of Building Services Engineers, 2005.

[4] P. Heiselberg, M. Sandberg, Evaluation of discharge coefficients for window openings in wind driven natural ventilation, International journal of ventilation 5 (1) (2006) 43-52.

[5] B. Jones, R. Kirby, Indoor air quality in uk school classrooms ventilated by natural ventilation windcatchers, International Journal of Ventilation 10 (4) (2012) 323-337.

[6] D. Etheridge, A perspective on fifty years of natural ventilation research, Building and Environment 91 (2015) 51-60.

[7] D. Etheridge, Natural ventilation of buildings: theory, measurement and design, John Wiley \& Sons, 2012.

[8] CIBSE, Environmental Design: CIBSE Guide A, Chartered Institution of Building Services Engineers, 2016. 
[9] P. Heiselberg, Natural ventilation design, International journal of ventilation 2 (4) (2004) 295-312.

[10] ASHRAE, ASHRAE handbook fundamentals - SI edition, American Society of Heating, Refrigeration and Air-Conditioning Engineers, 2017.

[11] M. Orme, M. W. Liddament, A. Wilson, Numerical data for air infiltration and natural ventilation calculations, Air Infiltration and Ventilation Centre Bracknell, 1998.

[12] B. Vickery, C. Karakatsanis, External wind pressure distributions and induced internal ventilation flow in low-rise industrial and domestic structures, ASHRAE transactions 93 (1987) 2198-2213.

[13] M. Sandberg, An alternative view on the theory of cross-ventilation, International journal of ventilation 2 (4) (2004) 409-418.

[14] N. C. Daish, G. C. da Graça, P. F. Linden, D. Banks, Impact of aperture separation on wind-driven single-sided natural ventilation, Building and Environment 108 (2016) 122-134.

[15] M. Kolokotroni, P. K. Heiselberg, Ventilative cooling: State-of-the-art review, Tech. rep., International Energy Agency Energy Energy in Communities and Buildings Programme (2015).

[16] F. Flourentzou, J. Van der Maas, C.-A. Roulet, Natural ventilation for passive cooling: measurement of discharge coefficients, Energy and buildings 27 (3) (1998) 283-292. 
[17] British Standards Institute, BS EN 13141-1:2019 ventilation for buildings - performance testing of components/products for residential ventilation - part 1: Externally and internally mounted air transfer devices, Technical standards, British standards institute (2019).

[18] Smoke Control Association, Guidance on smoke control to common escape routes in apartment buildings (flats and maisonettes), Federation of Environmental Trade Associations, 2015.

[19] D. W. Etheridge, M. Sandberg, Building ventilation: theory and measurement, Vol. 50, John Wiley \& Sons Chichester, UK, 1996.

[20] T. S. Larsen, P. Heiselberg, Single-sided natural ventilation driven by wind pressure and temperature difference, Energy and Buildings 40 (6) (2008) 1031-1040.

[21] C.-R. Chu, Y.-H. Chiu, Y.-T. Tsai, S.-L. Wu, Wind-driven natural ventilation for buildings with two openings on the same external wall, Energy and Buildings 108 (2015) 365-372.

[22] P. Linden, G. Lane-Serff, D. Smeed, Emptying filling boxes: the fluid mechanics of natural ventilation, Journal of Fluid Mechanics 212 (1990) 309-335.

[23] Y. Chiu, D. Etheridge, External flow effects on the discharge coefficients of two types of ventilation opening, Journal of Wind Engineering and Industrial Aerodynamics 95 (4) (2007) 225-252.

[24] G. V. Fracastoro, G. Mutani, M. Perino, Experimental and theoretical 
analysis of natural ventilation by windows opening, Energy and Buildings 34 (8) (2002) 817-827.

[25] H. Shetabivash, Investigation of opening position and shape on the natural cross ventilation, Energy and Buildings 93 (2015) 1-15.

[26] C.-R. Chu, B.-F. Chiang, Wind-driven cross ventilation in long buildings, Building and environment 80 (2014) 150-158.

[27] M. Shirzadi, P. A. Mirzaei, M. Naghashzadegan, Development of an adaptive discharge coefficient to improve the accuracy of crossventilation airflow calculation in building energy simulation tools, Building and Environment 127 (2018) 277-290.

[28] M. Caciolo, P. Stabat, D. Marchio, Full scale experimental study of single-sided ventilation: analysis of stack and wind effects, Energy and Buildings 43 (7) (2011) 1765-1773.

[29] H. Cruz, J. C. Viegas, On-site assessment of the discharge coefficient of open windows, Energy and Buildings 126 (2016) 463-476.

[30] H. Wang, P. Karava, Q. Chen, Development of simple semiempirical models for calculating airflow through hopper, awning, and casement windows for single-sided natural ventilation, Energy and Buildings 96 (2015) 373-384.

[31] G. P. Bot, Greenhouse climate: from physical processes to a dynamic model, Thesis, Landbouwhogeschool te Wageningen (1983). 
[32] T. De Jong, G. Bot, Flow characteristics of one-side-mounted windows, Energy and buildings 19 (2) (1992) 105-112.

[33] V. V. Baturin, Fundamentals of industrial ventilation., Pergamon Press Ltd Headington Hill Hall, Oxford., 1972.

[34] J. von Grabe, Flow resistance for different types of windows in the case of buoyancy ventilation, Energy and Buildings 65 (2013) 516-522.

[35] P. Warren, L. Parkins, Single-sided ventilation through open windows, in: Windows in building design and maintenance, 1984, pp. 209-228.

[36] B. M. Jones, R. Kirby, Quantifying the performance of a top-down natural ventilation windcatcher ${ }^{\mathrm{TM}}$, Building and Environment 44 (9) (2009) 1925-1934.

[37] M. Serag-Eldin, Prediction of performance of a wind-driven ventilation device, Journal of Wind Engineering and Industrial Aerodynamics $97(11-12)(2009)$ 560-572.

[38] P. Heiselberg, K. Svidt, P. V. Nielsen, Characteristics of airflow from open windows, Building and Environment 36 (7) (2001) 859-869.

[39] CIBSE, Ventilation and Ductwork: CIBSE Guide B2, Chartered Institution of Building Services Engineers, 2016.

[40] D. Wilson, D. Kiel, Gravity driven counterflow through an open door in a sealed room, Building and Environment 25 (4) (1990) 379-388.

[41] Department for Education and Skills (DfES), Building bulletin 101, 2018: A design guide: Ventilation of school buildings (2018). 
[42] P. Holzer, T. C. Psomas, Ventilative cooling sourcebook: Energy in buildings and communities programme. march 2018, Tech. rep., International Energy Agency Energy Energy in Communities and Buildings Programme (2018).

[43] British Standards Institute, BS EN 13141-5:2019 ventilation for buildings - performance testing of components/products for residential ventilation - part 5: Cowls and roof outlet terminal devices, Technical standards, British standards institute (2019).

[44] B. Bailey, J. Montero, J. P. Parra, A. Robertson, E. Baeza, R. Kamaruddin, Airflow resistance of greenhouse ventilators with and without insect screens, Biosystems Engineering 86 (2) (2003) 217-229.

[45] M. Sherman, A power-law formulation of laminar flow in short pipes, Journal of Fluids Engineering 114 (4) (1992).

[46] M. Hall, Untersuchungen zum thermisch induzierten luftwechselpotential von kippfenstern, Bauphysik 26 (3) (2004) 109-115.

[47] P. F. Linden, The fluid mechanics of natural ventilation, Annual review of fluid mechanics 31 (1) (1999) 201-238.

[48] J. Seifert, Y. Li, J. Axley, M. Rösler, Calculation of wind-driven cross ventilation in buildings with large openings, Journal of Wind Engineering and Industrial Aerodynamics 94 (12) (2006) 925-947.

[49] J. von Grabe, P. Svoboda, A. Bäumler, Window ventilation efficiency in the case of buoyancy ventilation, Energy and Buildings 72 (2014) $203-211$. 
[50] W. S. Dols, B. J. Polidoro, Contam user guide and program documentation version 3.2, Tech. rep., NIST (2015).

[51] B. Jones, R. Lowe, M. Davies, Z. Chalabi, P. Das, I. Ridley, Modelling uniformly porous facades to predict dwelling infiltration rates, Building Services Engineering Research and Technology 35 (4) (2014) 408-416.

[52] A. Iqbal, H. Wigo, P. Heiselberg, A. Afshari, Effect of opening the sash of a centre-pivot roof window on wind pressure coefficients, International Journal of Ventilation 13 (3) (2014) 273-284.

[53] A. Mochida, H. Yoshino, T. Takeda, T. Kakegawa, S. Miyauchi, Methods for controlling airflow in and around a building under cross-ventilation to improve indoor thermal comfort, Journal of Wind Engineering and Industrial Aerodynamics 93 (6) (2005) 437-449.

[54] T. Kurabuchi, M. Ohba, T. Endo, Y. Akamine, F. Nakayama, Local dynamic similarity model of cross-ventilation part 1-theoretical framework, International Journal of Ventilation 2 (4) (2004) 371-382.

[55] M. Ohba, T. Kurabuchi, E. Tomoyuki, Y. Akamine, M. Kamata, A. Kurahashi, Local dynamic similarity model of cross-ventilation part 2application of local dynamic similarity model, International Journal of Ventilation 2 (4) (2004) 383-394.

[56] British Standards Institute, BS EN 16798-7:2017 energy performance of buildings - ventilation for buildings - part 7: Calculation methods for the determination of air flow rates in buildings including infiltration, Technical standards, British standards institute (2017). 
[57] J. Cockroft, P. Robertson, Ventilation of an enclosure through a single opening, Building and Environment 11 (1) (1976) 29-35.

[58] H. Wang, Q. Chen, A new empirical model for predicting single-sided, wind-driven natural ventilation in buildings, Energy and Buildings 54 (2012) 386-394.

[59] H. Wang, Q. Y. Chen, Modeling of the impact of different window types on single-sided natural ventilation, Energy Procedia 78 (2015) 15491555 .

[60] W. De Gids, H. Phaff, Ventilation rates and energy consumption due to open windows: a brief overview of research in the netherlands, Air infiltration review 4 (1) (1982) 4-5.

[61] British Standards Institute, BS EN 15242:2007 ventilation for buildings - calculation methods for the determination of air flow rates in buildings including infiltration, Technical standards, British standards institute (2007).

[62] British Standards Institute, BS EN 12101-2:2017 smoke and heat control systems - part 2: Natural smoke and heat exhaust ventilators, Technical standards, British standards institute (2017). 